\title{
FLIGHT-DETERMINED SUBSONIC LIFT AND DRAG CHARACTERISTICS OF SEVEN LIFTING-BODY AND WING-BODY REENTRY VEHICLE CONFIGURATIONS WITH TRUNCATED BASES
}

\author{
Edwin J. Saltzman \\ Analytical Services \& Materials \\ Edwards, California \\ K. Charles Wang ${ }^{\dagger}$ \\ The Aerospace Corporation \\ El Segundo, California \\ Kenneth W. Iliff ${ }^{*}$ \\ NASA Dryden Flight Research Center \\ Edwards, California
}

\begin{abstract}
$\underline{\text { Abstract }}$
This paper examines flight-measured subsonic lift and drag characteristics of seven lifting-body and wingbody reentry vehicle configurations with truncated bases. The seven vehicles are the full-scale M2-F1, M2-F2, HL-10, X-24A, X-24B, and X-15 vehicles and the Space Shuttle prototype. Lift and drag data of the various vehicles are assembled under aerodynamic performance parameters and presented in several analytical and graphical formats. These formats unify the data and allow a greater understanding than studying the vehicles individually allows. Lift-curve slope data are studied with respect to aspect ratio and related to generic wind-tunnel model data and to theory for lowaspect-ratio planforms. The proper definition of reference area was critical for understanding and comparing the lift data. The drag components studied include minimum drag coefficient, lift-related drag, maximum lift-to-drag ratio, and, where available, base pressure coefficients. The effects of fineness ratio on forebody drag were also considered. The influence of forebody drag on afterbody (base) drag at low lift is

\footnotetext{
"Edwin J. Saltzman, Senior Research Engineer.

${ }^{\dagger} \mathrm{K}$. Charles Wang, Member of the Technical Staff, Member, AIAA.

Kenneth W. Iliff, Chief Scientist, Fellow, AIAA.

Copyright (C) 1999 by the American Institute of Aeronautics and Astronautics, Inc. No copyright is asserted in the United States under Title 17, U.S. Code. The U.S. Government has a royalty-free license to exercise all rights under the copyright claimed herein for Governmental purposes. All other rights are reserved by the copyright owner.
}

shown to be related to Hoerner's compilation for body, airfoil, nacelle, and canopy drag. These analyses are intended to provide a useful analytical framework with which to compare and evaluate new vehicle configurations of the same generic family.

\section{Nomenclature}

A

$A_{b}$

$A_{c}$

$a_{l}$

$a_{n}$

$A_{\text {w }}$

$b$

c

\section{$C_{D}$}

$C_{D_{b}}$

$C_{D_{b}}{ }^{\prime}$

$C_{D_{0}}$

$C_{D_{\text {fore } b}}$ aspect ratio, $A=b^{2} / S$

base area, $\mathrm{ft}^{2}$

maximum projected cross-sectional area, $\mathrm{ft}^{2}$

longitudinal acceleration, $g$

normal acceleration, $g$

wetted area, $\mathrm{ft}^{2}$

span, $\mathrm{ft}$

base pressure profile factor,

$$
c=C_{D_{b}} / C_{D_{b}}{ }^{\prime}
$$

drag coefficient, $C_{D}=D / \bar{q} S$

base drag coefficient, using derived base pressure profile (reference area is $A_{b}$ for equations (8) and (9); reference area is $S$ for equations (11), (12), and (13))

base drag coefficient, assuming "flat" base pressure profile (reference area is $S$ )

zero-lift drag coefficient

forebody drag coefficient referenced to $A_{b}$ 


\begin{tabular}{|c|c|}
\hline$C_{D_{\text {fore }, S}}$ & forebody drag coefficient referenced to $S$ \\
\hline$C_{D_{\min }}$ & $\begin{array}{l}\text { minimum drag coefficient at vertex of drag } \\
\text { polar }\end{array}$ \\
\hline$C_{F}$ & $\begin{array}{l}\text { turbulent boundary-layer skin friction } \\
\text { coefficient (over wetted surfaces) }\end{array}$ \\
\hline$C_{F_{e}}$ & $\begin{array}{l}\text { equivalent skin friction coefficient } \\
\text { (includes all drag components at } C_{D_{\min }}\end{array}$ \\
\hline$C_{F_{e}}{ }^{\prime}$ & $\begin{array}{l}\text { equivalent skin friction coefficient of the } \\
\text { forebody alone }\end{array}$ \\
\hline$C_{L}$ & lift coefficient, $C_{L}=L / \bar{q} S$ \\
\hline$C_{L_{\alpha}}$ & $\begin{array}{l}\text { lift-curve slope (with respect to } \alpha \text { ), } \mathrm{deg}^{-1} \\
\text { or } \operatorname{rad}^{-1}\end{array}$ \\
\hline$C_{L_{\min }}$ & $\begin{array}{l}\text { lift coefficient for minimum drag } \\
\text { coefficient }\end{array}$ \\
\hline$C_{P_{b}}$ & $\begin{array}{l}\text { base pressure coefficient, } \\
\qquad C_{P_{b}}=\left(p_{b}-p\right) / \bar{q}\end{array}$ \\
\hline$D$ & drag force along flightpath, lb \\
\hline$D_{\min }$ & minimum drag at vertex of drag polar, $\mathrm{lb}$ \\
\hline$d_{e f f}$ & effective diameter, $d_{\text {eff }}=\sqrt{4 A_{c}} / \pi$ \\
\hline$f$ & equivalent parasite drag area, $\mathrm{ft}^{2}$ \\
\hline$g$ & gravitational acceleration \\
\hline$K$ & $\begin{array}{l}\text { base pressure factor (numerator coefficient } \\
\text { in Hoerner's equation for three- } \\
\text { dimensional configurations) }\end{array}$ \\
\hline$l$ & longitudinal length of a vehicle, $\mathrm{ft}$ \\
\hline$L$ & lift force normal to the flightpath, lb \\
\hline$L / D$ & lift-to-drag ratio \\
\hline$(L / D)_{\max }$ & maximum lift-to-drag ratio \\
\hline$M$ & free-stream Mach number \\
\hline$p$ & ambient pressure, $\mathrm{lb} / \mathrm{ft}^{2}$ \\
\hline$p_{b}$ & base static pressure, $1 \mathrm{~b} / \mathrm{ft}^{2}$ \\
\hline $\bar{q}$ & $\begin{array}{l}\text { free-stream dynamic pressure, } \mathrm{lb} / \mathrm{ft}^{2} \\
\quad \bar{q}=0.7 p M^{2}\end{array}$ \\
\hline$S$ & reference area, $\mathrm{ft}^{2}$ \\
\hline$W$ & vehicle weight, $1 \mathrm{~b}$ \\
\hline$\alpha$ & angle of attack, deg \\
\hline$\delta_{e}$ & elevon or elevator deflection, deg \\
\hline$\delta_{f}$ & flap deflection, deg \\
\hline$\delta_{L}$ & lower flap deflection, deg \\
\hline
\end{tabular}

$$
\begin{array}{ll}
\delta_{s b} & \text { speed-brake deflection, deg } \\
\delta_{U} & \text { upper flap deflection, deg } \\
\Delta & \text { uncertainty } \\
\Delta C_{D} & \text { increment in drag coefficient } \\
\Delta C_{D} / \Delta C_{L}{ }^{2} & \text { drag-due-to-lift factor } \\
\varepsilon & \text { Oswald lifting-efficiency factor, modified } \\
\Lambda & \text { wing or body sweep angle, deg } \\
& \underline{\text { Introduction }}
\end{array}
$$

In recent years, interest has been renewed in controlled reentry from low-Earth orbit and the Earth's upper atmosphere. This interest has been motivated by several factors: a growing commercial space launch market and its desire for a low-cost, reusable means of space access; the need for a crew return/rescue vehicle from the International Space Station; and the potential for future military space operations. Fundamental studies by the NACA ${ }^{\S}$ and NASA in the late 1950 's and early 1960's described three basic methods of atmospheric reentry: ballistic reentry, winged reentry, and wingless lifting-body reentry. The ballistic reentry approach necessitates the use of parachutes to land, but the lifting body and wing-body approaches provide the possibility of horizontal landings. Flight examples of these latter two approaches include the M2-F1, M2-F2, HL-10, X-24A, X-24B, and X-15 vehicles and the Space Shuttle. In addition, most lifting reentry configurations are attractive from the standpoint of volumetric efficiency, crossrange and downrange capability, peak acceleration and heating rates, and lowspeed handling qualities. Because of the current interest in lifting reentry shapes, this paper reexamines lift and drag characteristics of the seven aforementioned vehicles during subsonic unpowered flight, and presents a unified analysis of their subsonic aerodynamic performance that enables meaningful comparisons with new lifting reentry designs.

The vehicles examined in this paper, the M2-F1, M2-F2, HL-10, X-24A, X-24B, and X-15 vehicles and the Shuttle prototype, comprise a unique class of aircraft. Not only were the vehicles all lifting reentry

\footnotetext{
§The National Advisory Committee for Aeronautics (NACA) became incorporated into the National Aeronautics and Space Administration (NASA) in October 1958.

"The Shuttle prototype referred to in this paper is the nonorbiting Shuttle Enterprise. The Space Shuttle referred to is the Orbiter Columbia.
} 
shapes, they were all piloted and capable of routine unpowered horizontal landings. Each of these vehicles also had a truncated afterbody or blunt base, which resulted in base drag being a significant component of the total vehicle drag. In terms of planform design, all of the aforementioned vehicles had low-aspect ratios between 0.6 and 2.5. The lift and drag data of the vehicles presented herein were obtained during subsonic, unpowered, coasting flights performed at Edwards Air Force Base (California) between 1959 and 1977. The primary organizations involved were the NASA Dryden Flight Research Center ${ }^{\#}$ (Edwards, California) and the Air Force Flight Test Center; the U. S. Navy was also a partner in the X-15 program.

The purpose of this study is to assemble flightmeasured lift and drag data from these vehicles under common aerodynamic performance parameters or metrics (that is, the data from all seven vehicles are plotted together) in an attempt to unify the results for this class of vehicles. This array of data is intended to collectively yield information that might otherwise escape notice if the vehicles were studied individually. To accomplish this, the performance parameters of the subject vehicles have been related, or exposed, to data formats and standards that are based on theory and concepts that range from several decades to a century old (for example, the concepts of Jones; Allen and Perkins; Helmbold; Krienes; Oswald; and ultimately, Prandtl and Lanchester). Works that have been explicitly used will be referenced in following sections.

The innovative and intuitive concepts cited above were intended for vehicle configurations that are quite different than the subject vehicles. For example, the relevant Jones work applied to sharp-edged, low-aspectratio wings; Allen's and Perkins' related work addressed high-fineness-ratio bodies of revolution; and the concepts of the others applied to moderate-, high-, and even infinite-aspect-ratio wings. In other words, some of the concepts and standards employed herein were not originally intended to apply to the subject vehicles. Nevertheless, several such theoretical relationships and standards have been used as a means of organizing and assessing the flight results considered.

This study is ultimately intended to provide a useful database and analytical framework with which to compare and evaluate the subsonic aerodynamic performance of new vehicle configurations of the same

\footnotetext{
"NASA Dryden was called the NASA Flight Research Center at the time of the subject flight experiments.
}

generic family, low-aspect-ratio lifting reentry shapes with truncated bases. The results can also be used as a first-order design tool to help airframe designers define the outer mold lines of future configurations as well as assess the predictive techniques used in design and development.

Use of trade names or names of manufacturers in this document does not constitute an official endorsement of such products or manufacturers, either expressed or implied, by the National Aeronautics and Space Administration.

\section{Historical Background}

At a NACA conference held in March of 1958, manned satellites and alternative methods of reentering the Earth's atmosphere were comprehensively studied. ${ }^{1}$ Three different methods of reentry from Earth orbit were considered and discussed within the first four papers. The three methods were ballistic reentry, ${ }^{2}$ the wingless lifting body, ${ }^{3}$ and winged configurations. ${ }^{4}$ Reference 3 advocated the lifting body mainly on the basis that its hypersonic lift-to-drag ratio of approximately 0.5 would provide a maximum deceleration of approximately $2 \mathrm{~g}$, low enough to allow a pilot to intervene in the control of the vehicle during this portion of the reentry.

The first lifting-body concepts involved very blunt half-cones. ${ }^{3,5}$ Later, the concepts evolved into higherfineness-ratio cones, ${ }^{6-8}$ and the capability of achieving conventional (although unpowered) horizontal landings was discussed. Numerous wind-tunnel model tests were performed on candidate versions of the half-cone and shapes having flattened bottom surfaces. In 1962, Reed demonstrated unpowered horizontal landings and controllable flight with a miniature lightweight radiocontrolled model of an M2 half-cone configuration. ${ }^{9}$ This demonstration was followed by the construction of a lightweight M2 craft large enough to carry a pilot. This unpowered M2-F1 vehicle demonstrated controllable flight and horizontal landings for a maximum subsonic lift-to-drag ratio of 2.8. The M2-F1 lift, drag, and stability and control characteristics were published circa 1965 . $^{10,11}$

A heavier and modified version of the M2 shape was built and began flying in 1966. The resulting subsonic lift and drag data from flight were published in $1967 .^{12}$ Other lifting-body configurations (all capable of unpowered horizontal landings) were developed and flight-tested as well. The subsonic lift and drag characteristics have previously been reported for the 
$\mathrm{HL}-10,{ }^{13} \mathrm{X}-24 \mathrm{~A},{ }^{14}$ and $\mathrm{X}-24 \mathrm{~B}^{15}$ lifting bodies. More information on the evolution and flight testing of the lifting bodies is available. ${ }^{9,16-18}$

The M2-F1 and subsequent lifting bodies were not the pioneer vehicles for performing unpowered ("deadstick") landings, but they were the first very-low-aspectratio vehicles $(A<1.5)$ to routinely land without power. The early rocket-powered research vehicles (the $\mathrm{X}-1, \mathrm{X}-2$, and D-558-II aircraft) were designed for unpowered landings, but they had aspect ratios between 6 and 3.6. Later, the X-15 hypersonic research aircraft, which had an aspect ratio between the early rocketpowered vehicles and the lifting bodies, made routine dead-stick landings. The X-15 aircraft was designed to land unpowered ${ }^{19}$ based on the experience of the earlier rocket-powered aircraft having the higher aspect ratios and on a series of special landing investigations using low-aspect-ratio fighter-type airplanes. ${ }^{20}$ This study investigated approach and landings at lift-to-drag ratios of 2 to 4 and used extended gear and speed brakes to increase the drag. Lift and drag data for the X-15 aircraft have previously been published. ${ }^{19,21}$

Despite the success of the X-15 unpowered landing experience, the early planning for the Space Shuttle included "pop out" auxiliary engines to ensure safe horizontal landings. Thompson, an X-15 and liftingbody research pilot, argued that the $\mathrm{X}-15$ and liftingbody experience rendered landing engines for the Space Shuttle as an unnecessary weight and payload penalty. ${ }^{22}$ The Space Shuttle was ultimately designed to make unpowered landings, and thus became the heaviest of the reentry-type vehicles to use routine dead-stick landings. The low-speed lift and drag characteristics of the nonorbiting Shuttle prototype Enterprise have previously been published. ${ }^{23}$ Results have been reported for the Enterprise with and without a tailcone. $^{23}$ Only the truncated configuration-that is, without a tailcone-is considered in this paper.

Currently, new lifting reentry vehicles are being developed for rescue missions from space and to serve as reusable launch vehicles. These vehicles have much in common with the lifting bodies described herein and, if aspect ratio is increased somewhat, with the X-15 aircraft and the Shuttle prototype. This report presents the subsonic lift and drag characteristics of the M2-F1, M2-F2, HL-10, X-24A, X-24B, and X-15 vehicles and the Shuttle prototype Enterprise under unifying performance parameters and formats, with the intent of aiding the definition of exterior mold lines of future candidate reentry vehicles that perform horizontal landings.

As was mentioned in the "Introduction," some of the unifying metrics depend on borrowed concepts and standards that are several decades old and were originally intended for application on winged vehicles of high- or moderate-aspect ratio. The authors realize and accept that some readers may disagree with how the borrowed concepts and standards are applied herein. The formats, concepts, and standards that have been used, and the information that may be derived therefrom, are offered as a beginning in the quest for understanding the general nature of lift and drag for this unique class of vehicles. This "beginning" could not have occurred but for the seven flight research programs addressed herein and the dedicated technical personnel who processed, analyzed, and carefully documented the lift and drag data. The present authors are indebted to these earlier investigators for their attention to detail and comprehensive reporting.

The following information is included for the purpose of orientation and perspective.

$\begin{array}{ccc}\text { Earliest flight: } & \text { June } 8,1959 & \begin{array}{c}\text { X-15 aircraft } \\ \text { Lhuttle prototype } \\ \text { Enterprise }\end{array} \\ \begin{array}{c}\text { Most number } \\ \text { of flights: }\end{array} & 199 & \begin{array}{c}\text { X-15 aircraft } \\ \text { October 26,1977 }\end{array} \\ \begin{array}{c}\text { Least number } \\ \text { of flights: }\end{array} & 5 & \begin{array}{c}\text { Shuttle prototype } \\ \text { Enterprise }\end{array} \\ \text { Lightest vehicle: } & 1250 \mathrm{lb} & \begin{array}{c}\text { M2-F1 } \\ \text { lifting body }\end{array} \\ \text { Heaviest vehicle: } & 150,900 \mathrm{lb} & \begin{array}{c}\text { Shuttle prototype } \\ \text { Enterprise }\end{array}\end{array}$

The seven vehicles completed a combined total of 424 flights. Data from 6-7 percent of those flights were used for this paper.

\section{$\underline{\text { Methods of Analysis }}$}

This section assembles methods and metrics (performance parameters) used in the analysis of the subject lift and drag data. The primary metrics of aerodynamic performance include lift-curve slope; a modified Oswald lifting-efficiency factor; the drag-dueto-lift factor; maximum lift-to-drag ratio; and for minimum drag analysis, equivalent parasite drag area, equivalent skin friction coefficient, base pressure 
coefficient, base drag coefficient, and forebody drag coefficient.

\section{Lift-Curve Slope}

Trimmed lift-curve slope data for the subject vehicles are related to potential flow standards for finite-span wings. The most exact theoretical solution for unswept, rectangular wings at incompressible conditions is considered to be that derived by Krienes. ${ }^{24}$ Krienes' relationship for lift-curve slope, $C_{L_{\alpha}}$, and aspect ratio, $A$, is well-represented by the following relationship from Helmbold ${ }^{25}$ as expressed by Polhamus: ${ }^{26}$

$$
C_{L_{\alpha}}=\frac{2 \pi A}{\sqrt{A^{2}+4}+2} \quad\left(\operatorname{rad}^{-1}\right)
$$

At the lowest aspect ratios $(A<1.0)$, equation (1) merges with the linear relationship of Jones, ${ }^{27}$ which follows:

$$
C_{L_{\alpha}}=\frac{\pi A}{2}, \quad\left(\operatorname{rad}^{-1}\right)
$$

Equations (1) and (2) represent lift due to circulation. Neither of these relationships account for leading-edge vortex lift, such as is developed by highly swept delta wings, ${ }^{28}$ nor lift generated by vortices resulting from crossflow over the forebody. ${ }^{29-31}$ The relationships represented by equations (1) and (2) are each oblivious to the effects of trim. Although all seven vehicles violate the limitations of equations (1) and (2), these equations are considered to be rational standards for evaluating the relative lifting capability of the subject configurations. The slopes for the lift curves of the present study were obtained over the lift coefficient range extending from the lowest lift coefficient achieved for a given maneuver to a lift coefficient greater than that required to obtain maximum lift-to-drag ratio.

\section{Lift-Related Drag}

The metrics used to evaluate the lift-related drag of the subject vehicles are the drag-due-to-lift factor, $\Delta C_{D} / \Delta C_{L}^{2} ;$ and the modified Oswald liftingefficiency factor, $\varepsilon,{ }^{32}$ which is a measure of the spanwise distribution of lift. The Oswald factor as applied herein has been modified as proposed by Wendt: ${ }^{33}$

$$
\varepsilon=\frac{\left(C_{L}-C_{L_{\min }}\right)^{2}}{\pi A\left(C_{D}-C_{D_{\min }}\right)}
$$

In this modified form of Oswald's efficiency factor, $C_{L_{\min }}$ and $C_{D_{\min }}$ are the values of lift and drag coefficient at the vertex of the parabolic or nearly parabolic relationship of $C_{L}$ as a function of $C_{D}$ (that is, the drag polar), which does not necessarily occur at zero lift. This condition exists for five of the seven vehicles considered in this study. Both lift-related drag factors represent lift coefficients extending to greater than that required to obtain maximum lift-to-drag ratio.

\section{Maximum Lift-to-Drag Ratio}

The maximum value of $C_{L} / C_{D}$ (symbolized as $(L / D)_{\text {max }}$ ) achieved by each of the subject vehicles at subsonic speeds is presented as a function of $b^{2} / A_{w}$. This form of aspect ratio is referred to as the "wetted aspect ratio." 34 This presentation includes a reference framework consisting of a family of curves representing constant values of equivalent skin friction coefficient, $C_{F_{e}}$, which is a form of minimum drag coefficient, $C_{D_{\min }}$ (which includes both forebody and base drag). Thus, if

$$
C_{D_{\min }}=\frac{D_{\min }}{\bar{q} S}
$$

then

$$
C_{F_{e}}=C_{D_{\min }} \frac{S}{A_{w}}
$$

Although $C_{F}$ is called the "equivalent skin friction coefficient," the operative word is "equivalent" because $C_{F_{e}}$ contains base drag, separation losses, protuberance drag, and other losses in addition to skin friction. The family of reference curves is analogous to that employed by Stinton, ${ }^{35}$ and the curves are defined by the following often-used expression from Loftin: ${ }^{36}$

$$
(L / D)_{\max }=\frac{1}{2} \sqrt{\frac{\pi A \varepsilon}{C_{D_{\min }}}}
$$

\section{Minimum Drag of the Vehicle}

Minimum drag is considered in several formats. When the lift coefficient and drag coefficient are based on vehicle planform reference area, the minimum drag coefficient can be defined as noted earlier in equation (4). The discussion on maximum lift-to-drag ratio also revealed that another metric for minimum drag 
coefficient is the equivalent skin friction coefficient (eq. (5)), which is obtained by basing the minimum drag coefficient on the wetted area, $A_{w}$. The wetted area for each vehicle is considered to be the wetted area of the respective forebody, which includes the body and wings or fins, and is thus the sum of all outer mold-line surfaces ahead of an associated base or trailing edge.

Another format for comparing minimum drag for various configurations is called the equivalent parasite drag area, $f$. This metric is related to equation (4) but eliminates the controversy regarding the choice of reference area by being defined as follows:

$$
f=C_{D_{\min }} S=\frac{D_{\min }}{\bar{q}}, \quad\left(\mathrm{ft}^{2}\right)
$$

Use of equivalent skin friction coefficient, $C_{F}$ (eq. (5)), and equivalent parasite drag area, $f$ (eq. (7)), is common among aircraft designers. An early example of their use is given in reference 37 .

Thus far, minimum drag has been represented as $C_{D_{\min }}$, where the reference area is the vehicle planform area, $S$, which is sometimes defined subjectively; $C_{F_{e}}$, where the reference area is the forebody wetted area, $A_{w}$, which can be defined objectively and accurately; or as $f$, where reference area is eliminated as a factor altogether. Despite any confusion that might result from such names as "equivalent skin friction coefficient" and "equivalent parasite drag area," each of the metrics presented above for minimum drag should be understood to include all losses caused by the forebody (that is, body plus fins, protuberances, control surfaces, and, if applicable, wings) as well as the drag caused by all base surfaces. Mathematically speaking, the following exists:

$$
C_{D_{\min }}=C_{D_{\text {fore }, S}}+C_{D_{b}} \frac{A_{b}}{S}
$$

and

$$
C_{F_{e}}=C_{F_{e}}{ }^{\prime}+C_{D_{b}} \frac{A_{b}}{A_{w}}
$$

where $C_{D_{\text {fore }, S}}$ is the forebody drag coefficient referenced to $S, C_{F_{e}}$ ' is the equivalent skin friction coefficient due to forebody only, $C_{D_{b}}$ is the coefficient of base drag, and $A_{b}$ is the base area.

\section{Minimum Forebody Drag}

Significant forebody drag losses exist in addition to the losses caused by skin friction alone. A way to quantify the sum of these losses is to compare the measured minimum drag of a vehicle with the sum of the measured base drag and the calculated skin friction drag for completely attached, turbulent, boundary-layer flow. The difference that results from this comparison represents losses from multiple sources, which are designated "excess forebody drag." The calculated, idealized, sum of the base drag and skin friction drag for each vehicle is obtained from:

$$
C_{F_{e}}=C_{F}+\left|C_{P_{b}}\right| \frac{A_{b}}{A_{w}} c
$$

where $C_{F}$ is the turbulent skin friction coefficient (calculated) of the forebody and $c$ is a base pressure profile factor.

The values of $C_{F}$, representing idealized forebody losses, have been calculated for each of the vehicles at the various flight conditions; adjusted for compressibility effects by the reference temperature method as applied by Peterson; ${ }^{38}$ and adjusted for form factor (three-dimensionality) by the coefficient, 1.02, as recommended for conical flow. ${ }^{39}$ The value of $C_{F}$ used to calculate the reference curves presented herein is 0.0023 , which is the average $C_{F}$ of the various vehicles. The constant, $c=0.92$, is a base pressure profile factor that will be explained in the following section.

\section{Base Pressure Profile Factor}

A common practice by wind-tunnel and flight experimenters has been to define a base drag coefficient increment as:

$$
C_{D_{b}}=\left|C_{P_{b}}\right| \frac{A_{b}}{S}
$$

where $C_{P_{b}}$ is obtained from a few scattered pressure measurements within the confines of the base surface. Thus, equation (11) is based on the assumption that the base pressure profile (consisting of the average of the pressures measured within a specific base region) was flat to the very edge of the base. However, the pressure profile is known to be somewhat rounded along the edges. Nevertheless, the flat profile approximation was usually used, mainly because making the numerous measurements required to define the profile was not 
practical. The factor, $c$, is used here to account for the rounded edges of the pressure profiles.

For example, the base drag increments for the X-15 aircraft ${ }^{21}$ are derived from the base pressure data ${ }^{40}$ using the flat profile assumption. However, when the resulting "flat profile" base drag increment is subtracted from the total zero-lift drag, the resulting forebody drag coefficient, based on wetted area, is approximately 0.0011 for $M=0.65$. For forebody drag, this increment is clearly too small, being only one-half of what the turbulent boundary-layer skin friction coefficient should be for the given flight conditions.

As a practical matter based upon the X-15 flight experience, no regions of laminar flow existed. Considering, therefore, overall turbulent flow for surfaces ahead of each base element and accounting for the skin temperature at subsonic speeds following coastdown from hypersonic speeds, ${ }^{41-43}$ the friction drag component has been calculated for the Mach numbers and Reynolds numbers of interest here. ${ }^{38,39}$ The subsonic drag of the blunt leading edges and the several protuberances that were exposed to the flow was estimated using guidelines from reference 31 . The resultant-more realistic-forebody drag is the sum of the friction drag, the leading-edge drag, and the protuberance drag for low-lift coefficients. The more correct base drag coefficient may now be defined as:

$$
C_{D_{b}}=C_{D_{0}}-C_{D_{\text {fore }, S}}
$$

where each factor is based on reference area, $S$, and $C_{D_{b}}$ is representative of the real (natural) base pressure profile. The former base drag coefficient, based on an assumed flat base pressure profile, is designated as $C_{D_{b}}{ }^{\prime}$.

From these analyses, a base pressure profile factor, $c$, can be defined as:

$$
c=\frac{C_{D_{b}}}{C_{D_{b}}{ }^{\prime}}=0.92
$$

This constant, $c$, is the same constant that appears in equation (10) for calculating the base drag component of $C_{F_{e}}$, as used in the description of excess forebody drag. How well this profile factor represents the other vehicles is not known, but $c=0.92$ was used to calculate the base drag of all of the vehicles because it is the only profile factor known to be available for full- scale vehicles. The $\mathrm{X}-15$ configuration serves as a nearly ideal vehicle for defining the base pressure profile factor by the means described because of its known overwhelmingly turbulent boundary layer, the small projected boattail area, and the precisely defined base area that does not change with variations in longitudinal control positions. In contrast, for most of the lifting-body vehicles, longitudinal control variations can cause significant changes in base area.

\section{$\underline{\text { Base Pressure Coefficients }}$}

Flight-measured base pressure coefficients, base pressure coefficients derived from published incremental drag attributed to the base, and estimated base pressure coefficients derived from those of a closely related, afterbody-base configuration are compared with two analytical equations developed by Hoerner. $^{31}$ These equations were derived from windtunnel experiments of small-scale models. Hoerner's equation for three-dimensional axisymmetric bodies of revolution is as follows (where $K=0.029$ ):

$$
-C_{P_{b}}=\frac{K}{\sqrt{C_{D_{f o r e}, b}}}
$$

Hoerner's equation for quasi-two-dimensional base flow conditions that generate the well-known Kármán vortex street is:

$$
-C_{P_{b}}=\frac{0.135}{\left(C_{D_{\text {fore }, b}}\right)^{1 / 3}}
$$

\section{$\underline{\text { Lift and Drag Coefficients }}$}

The flight-measured lift and drag coefficients $\left(C_{L}\right.$ and $C_{D}$ ) for all seven vehicles were obtained by the accelerometer method. ${ }^{44,45}$ The operative relationships for subsonic unpowered gliding flight are:

$$
\begin{aligned}
& C_{L}=\left(a_{n} \cos \alpha+a_{l} \sin \alpha\right) \frac{W}{\bar{q} S} \\
& C_{D}=\left(a_{n} \sin \alpha-a_{l} \cos \alpha\right) \frac{W}{\bar{q} S}
\end{aligned}
$$

where $a_{n}$ and $a_{l}$ are the normal and longitudinal accelerations in $g$ units, $\alpha$ is the angle of attack, $W$ is the vehicle weight, $\bar{q}$ is the free-stream dynamic pressure, and $S$ is the reference area. 


\section{Data Uncertainty}

The accurate definition of lift and drag characteristics from flight data requires high quality sensors and careful attention to detail in sensor calibration and use. In general, lift and drag determination is most sensitive to error in the measurement of thrust, longitudinal and normal acceleration, angle of attack, static pressure, Mach number, vehicle weight, and an accounting of control deflections. For the seven vehicles considered here, thrust is not a factor where data were obtained during coasting flight, thus avoiding a major source of uncertainty. Some of the problems associated with the measurement of these quantities, and their relative importance, is discussed in reference 45 .

Uncertainty information has been published for four of the subject aircraft: the M2-F1, M2-F2, HL-10, and $\mathrm{X}-15$ vehicles. For the three lifting bodies, the sources list estimated measurement errors from sensors (that is, the standard deviation) along with the contribution of individual sensors to error in $C_{L}$ and $C_{D}$. Then the combined contribution of the sensors to uncertainty of $C_{L}$ and $C_{D}$ is given in the form of the "square root of the sum of the errors squared."10,12,13 For the X-15 aircraft, errors are presented in references 21 and 40 for Mach numbers higher than those considered here. Uncertainty in $C_{L}$ and $C_{D}$ for the X-15 aircraft has therefore been prepared based on unpublished data and through adjustments to the errors shown in references 21 and 40 for the effects of Mach number and dynamic pressure. Uncertainty in base pressure coefficient is available only for the M2-F1 and X-15 vehicles. Table 1 shows the uncertainties that are available from these four vehicles.

Table 1. Data uncertainties.

\begin{tabular}{cccc}
\hline \hline Vehicle & $\begin{array}{c}\Delta C_{L} / C_{L}, \\
\text { percent }\end{array}$ & $\begin{array}{c}\Delta C_{D} / C_{D}, \\
\text { percent }\end{array}$ & $\begin{array}{c}\Delta C_{P_{b}} / C_{P_{b}}, \\
\text { percent }\end{array}$ \\
\hline M2-F1 & \pm 3.0 & \pm 5.5 & \pm 7.0 \\
M2-F2 & \pm 1.7 & \pm 3.2 & Not available \\
HL-10 & \pm 3.2 & \pm 3.9 & Not available \\
X-15 & \pm 4.3 & \pm 3.9 & \pm 6.4 \\
\hline \hline
\end{tabular}

These uncertainties represent the square root of the sum of the squares for each of these coefficients when plotted as individual data points. Because these coefficients, as used in this paper, are obtained from curves faired through numerous data points, the uncertainty of the coefficients and other metrics should be smaller than shown in table 1.

Corresponding uncertainties are not available for the $\mathrm{X}-24 \mathrm{~A}$ and X-24B lifting bodies and the Shuttle prototype Enterprise; however, airdata system calibration procedures similar to those used on the other four vehicles are known to have been used on these three vehicles. In addition, lift and drag were obtained by the accelerometer method for all seven vehicles. Although the above table cannot be established as representing the uncertainties for the latter three vehicles, expecting their uncertainties to be relatively close to those listed in table 1 is not unreasonable.

\section{$\underline{\text { Results and Discussion }}$}

The results of the current study are presented and discussed under four subheadings: "Lift-Curve Slope," "Lift-Related Drag," "Lift-to-Drag Ratio," and several metrics of "Minimum Drag." Formats for collectively presenting the data are chosen in the hope that one or more formats will yield a greater understanding of the data than would likely occur by studying the subject vehicles individually.

\section{Lift-Curve Slope}

This section attempts to unify the lift capabilities of the seven flight vehicles previously discussed. The subsonic lift-curve slope data for these vehicles have been assembled from references 10, 12-15, 21, and 23. Data were obtained during gradual pushover/pullup maneuvers (consequently trimmed for the respective maneuvers) over a range of lift coefficient extending somewhat greater than that required to achieve maximum lift-to-drag ratio. These data are compared to conical wind-tunnel model data and to theory for verylow- and moderately-low-aspect ratios. Figure 1 shows three-view drawings of each of the seven vehicles and the M2-F3 lifting body. Schematic illustrations of control surfaces whose deflections influence base area are also shown for four lifting bodies (fig. 1).

Table 2 shows the data to be considered as derived from their respective references. The $C_{L_{\alpha}}$ and aspect-ratio values shown are, of course, subject to the values of the reference area, $S$, that were used in the various referenced documents. Use of the proper 


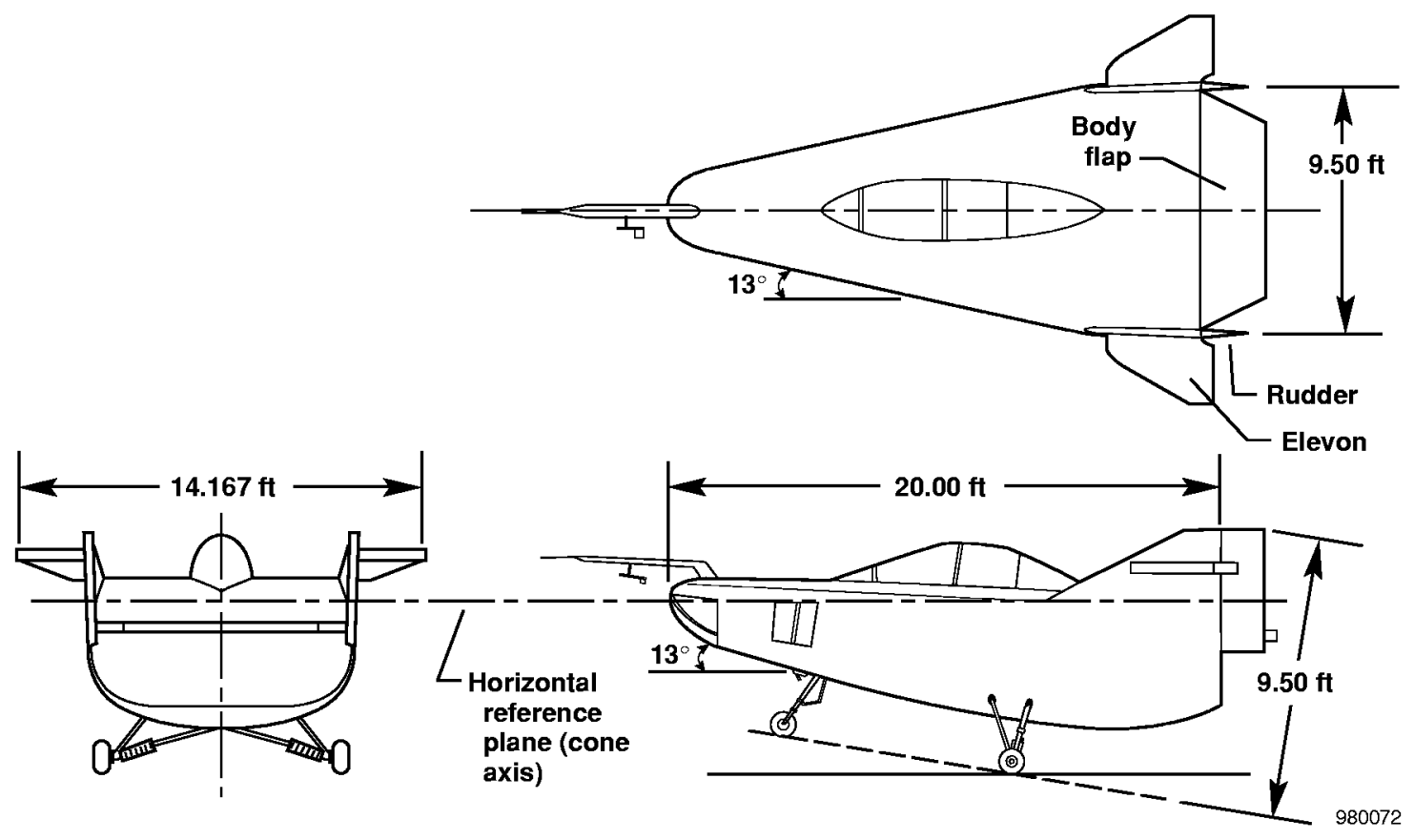

(a) The M2-F1 vehicle.
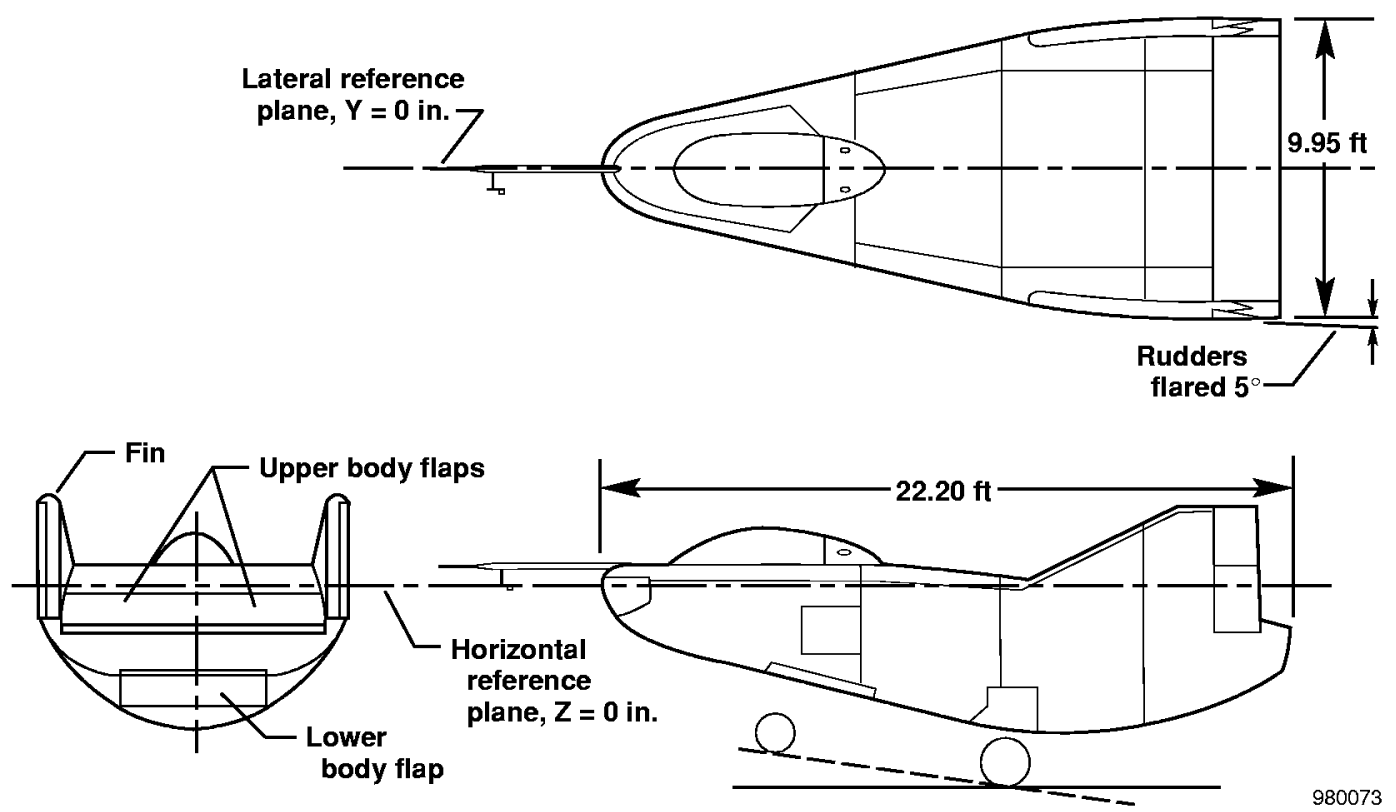

(b) The M2-F2 vehicle.

Figure 1. Three-view drawings of the subject vehicles. 

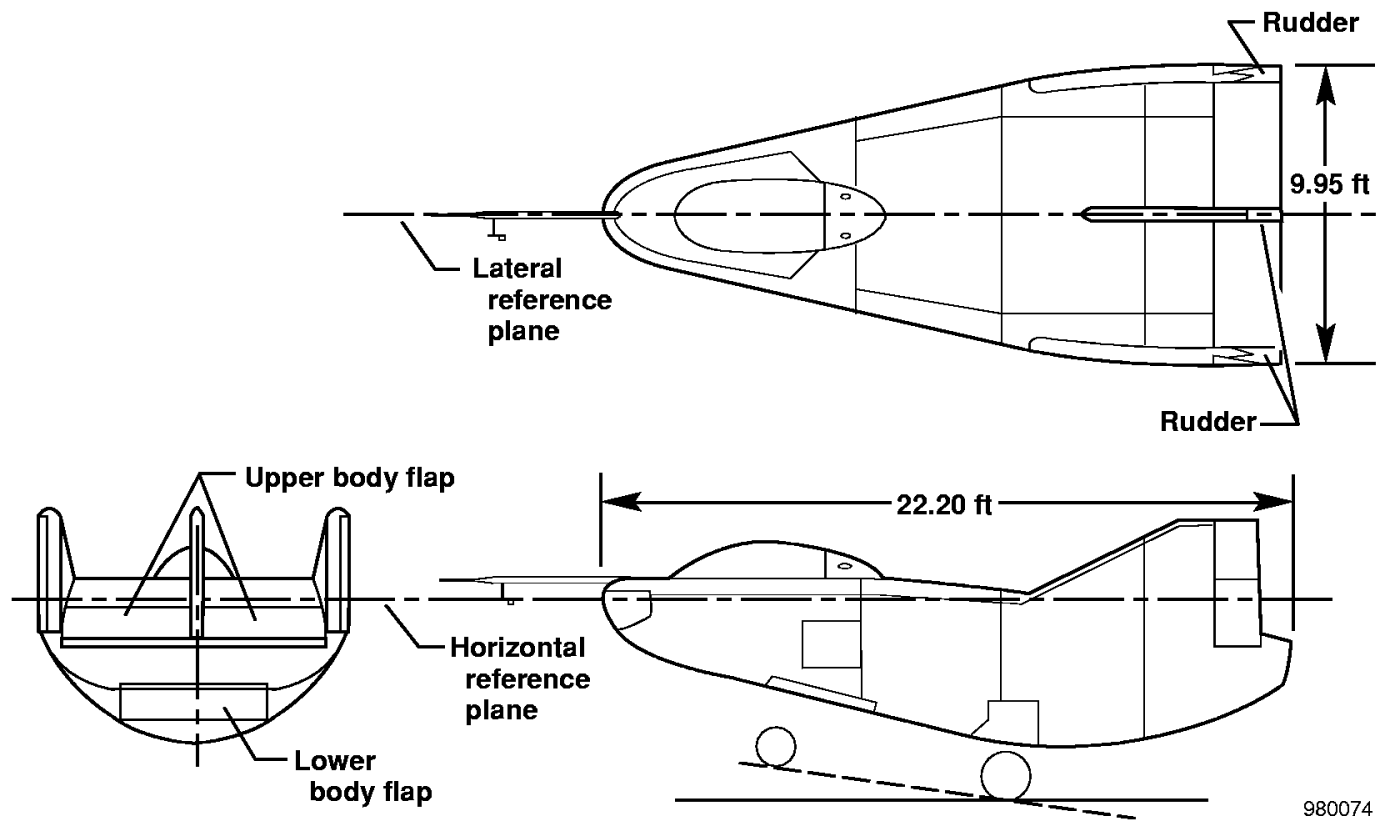

(c) The M2-F3 vehicle.

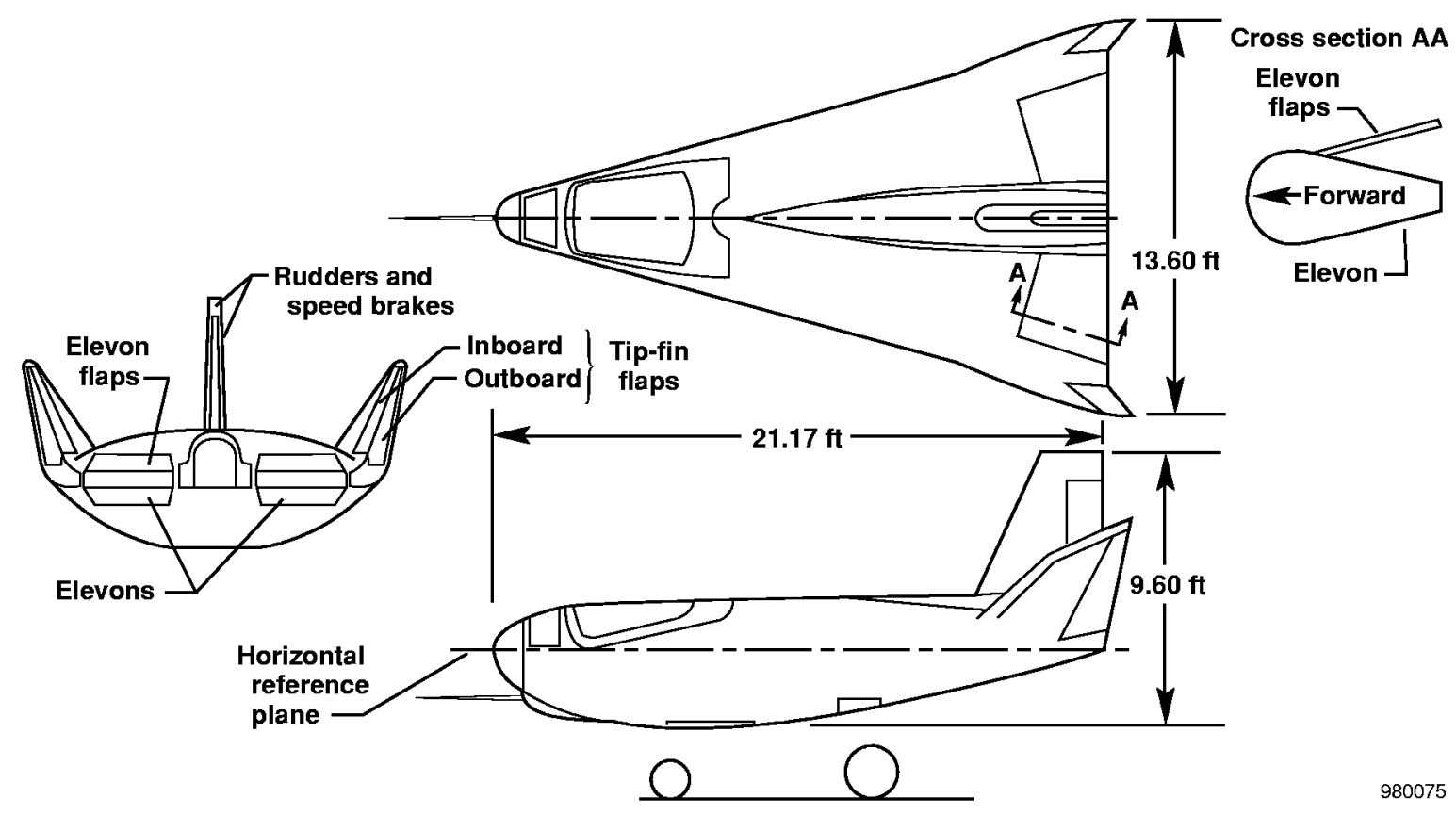

(d) The HL-10 vehicle.

Figure 1. Continued. 


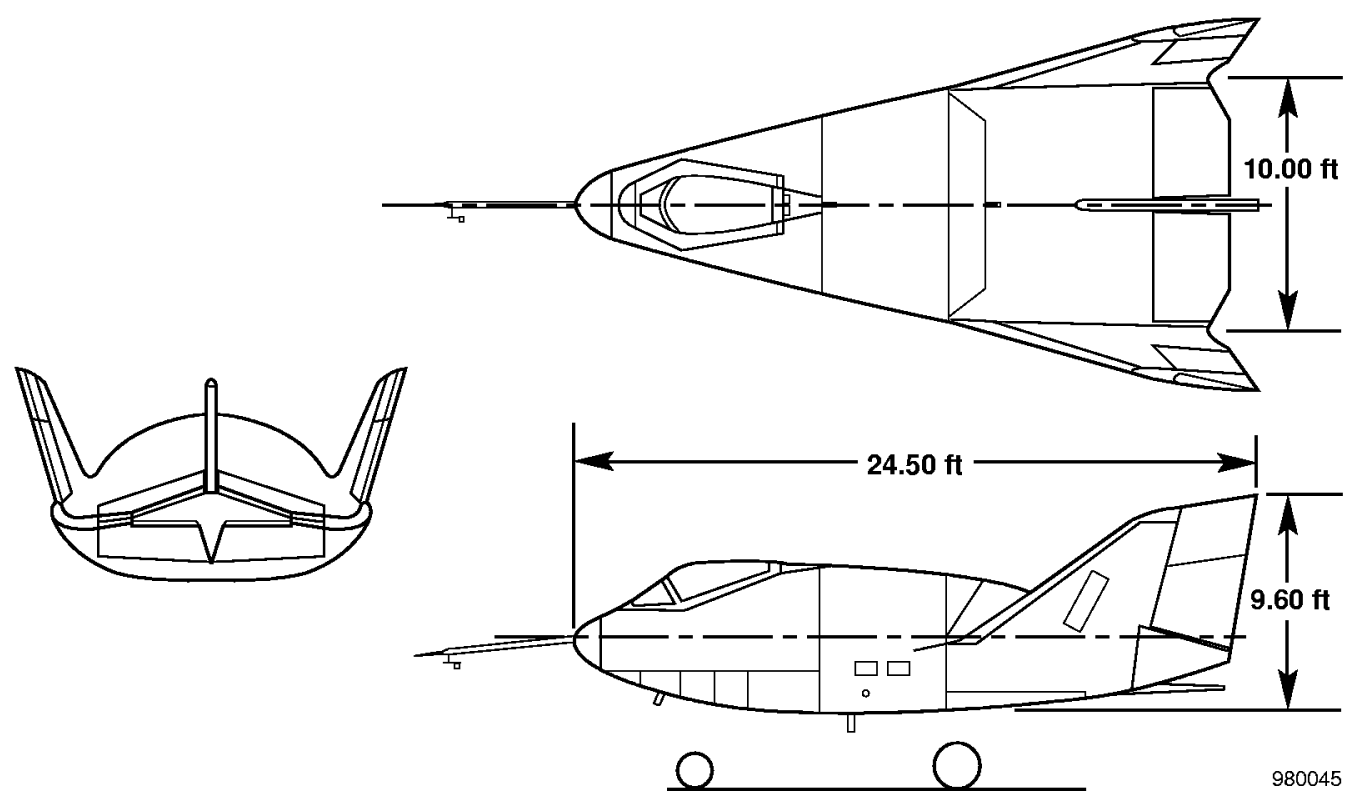

(e) The X-24A vehicle.

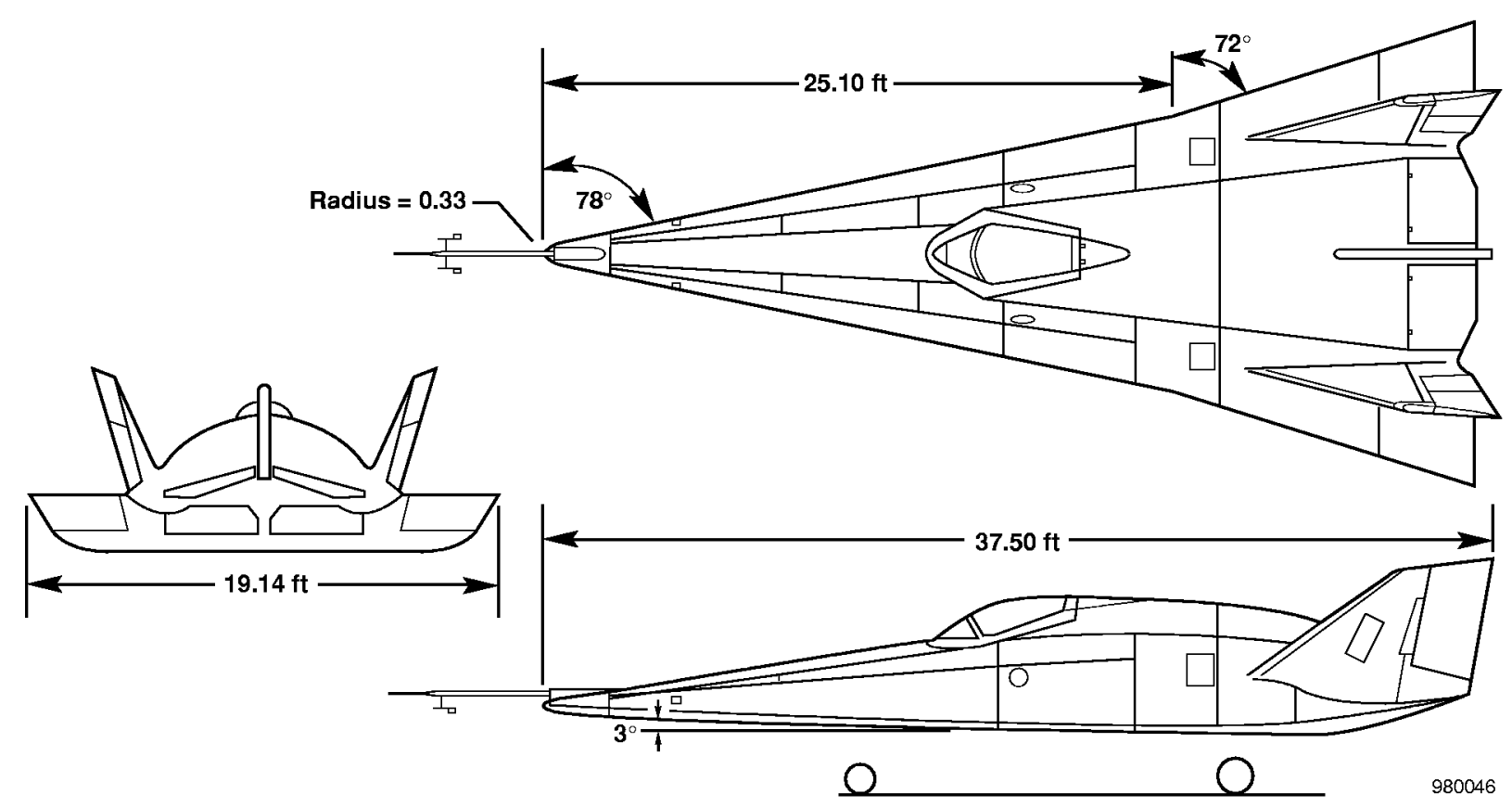

(f) The X-24B vehicle.

Figure 1. Continued. 


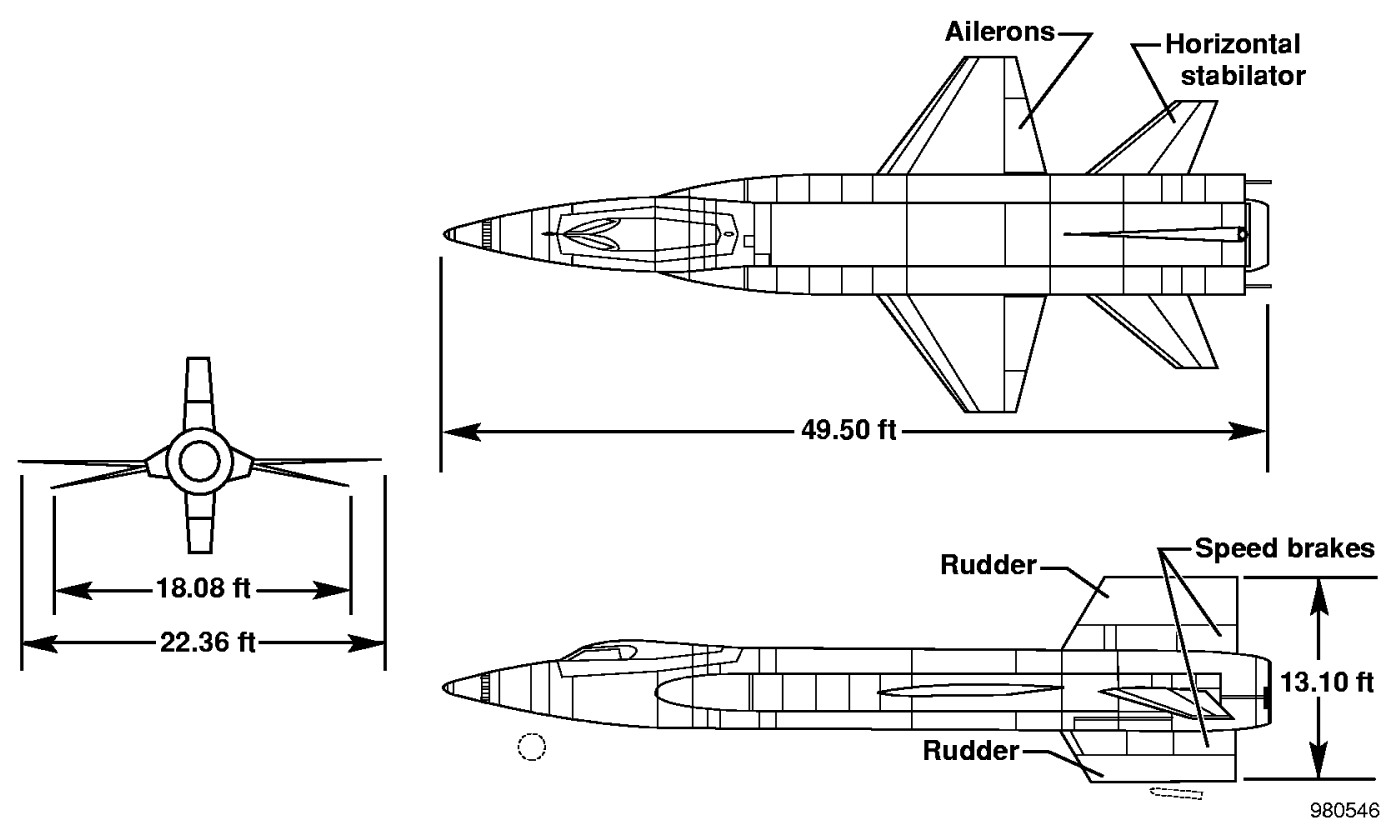

(g) The X-15 vehicle.

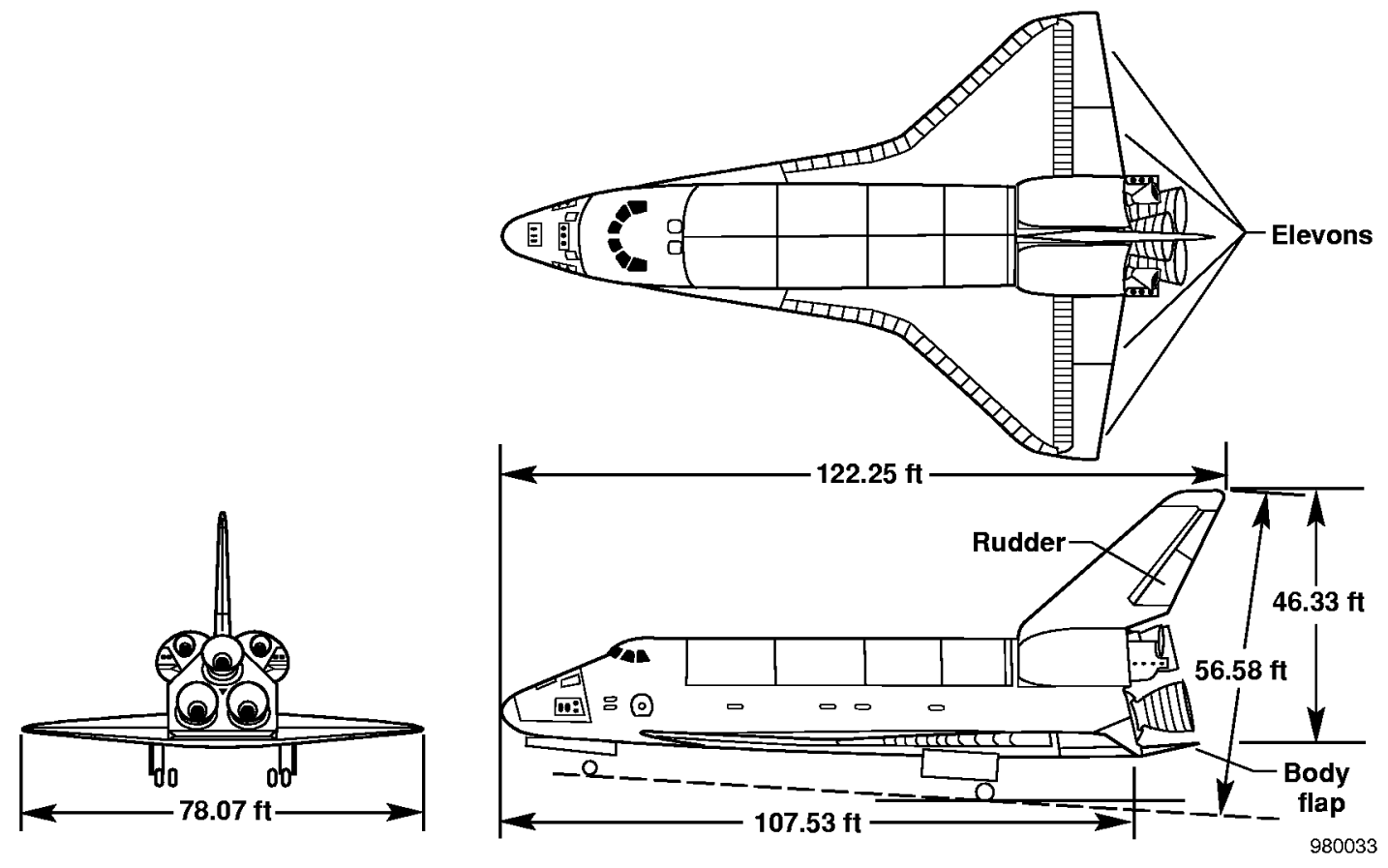

(h) The Space Shuttle.

Figure 1. Continued. 


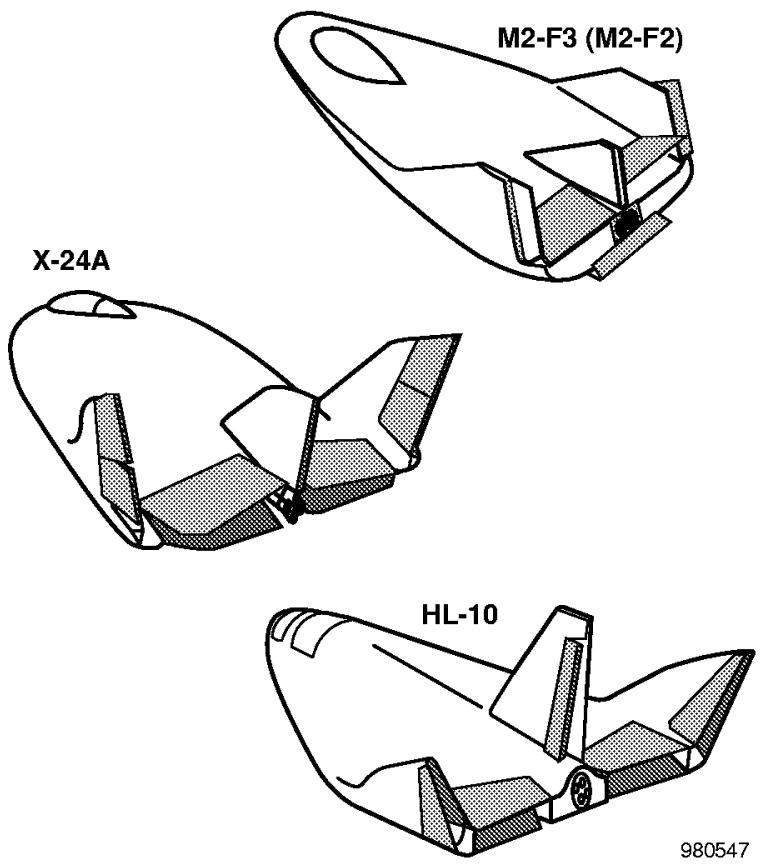

(i) Control surfaces that cause variable wedge angles. (Rudder and fin control surfaces are also shown.) The X-24A shaded items also apply to the X-24B lifting body.

Figure 1. Concluded. 


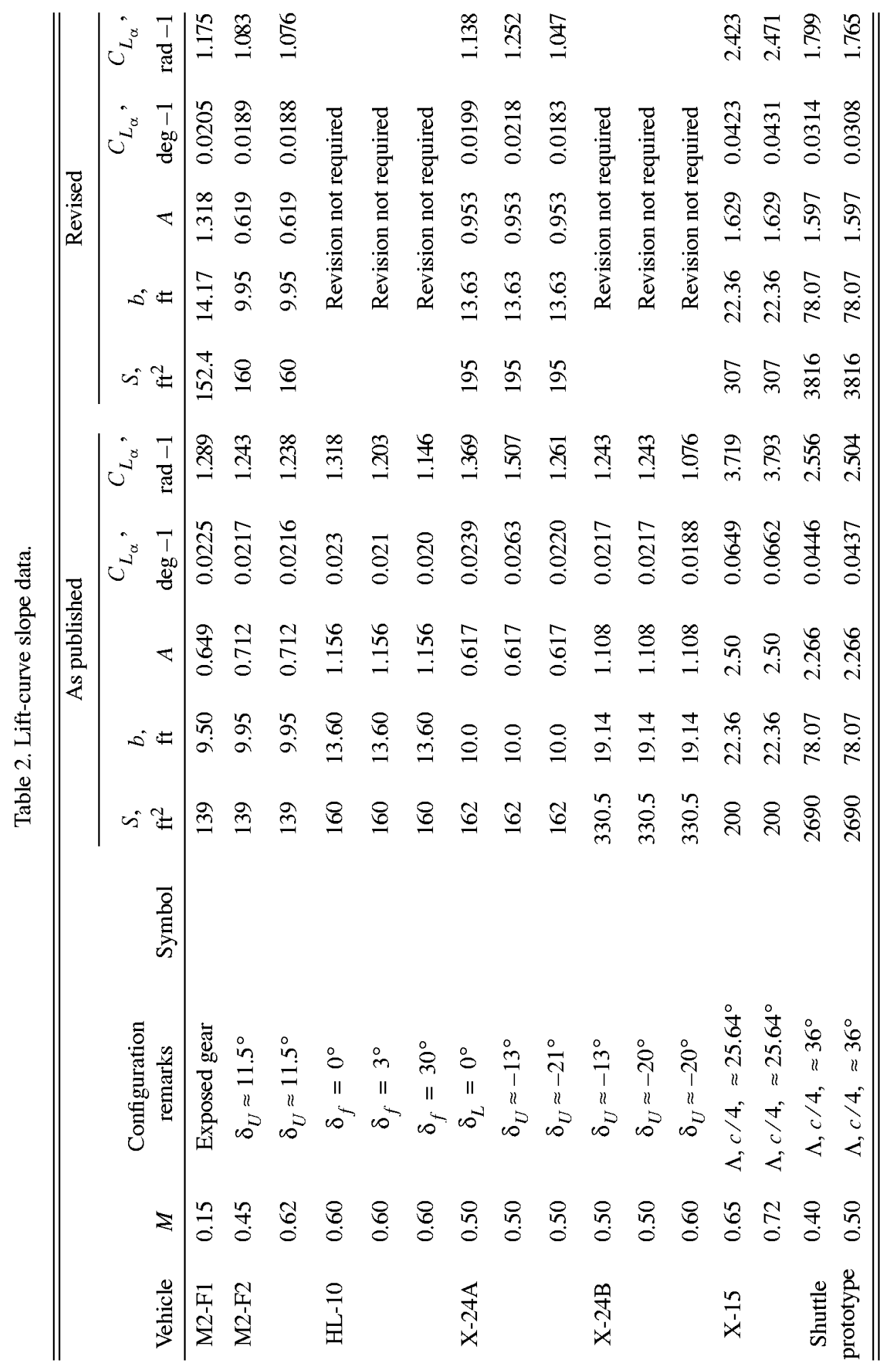


reference area and span is important towards achieving some understanding of how the lifting characteristics of the various configurations relate to each other, to generic wind-tunnel model data, and to theory.

Figure 2(a) shows the lift-curve slope data (the solid symbols) for five of the seven vehicles as published in the respective references plotted as functions of aspect ratio. Figure 2(a) also shows the relationships of $C_{L_{\alpha}}$ to aspect ratio as defined by Helmbold (eq. (1)) and, for the lowest aspect ratios, the linear relationship of Jones (eq. (2)). Neither of these relationships accounts for lift from vortices generated by sharp, highly swept leading edges.

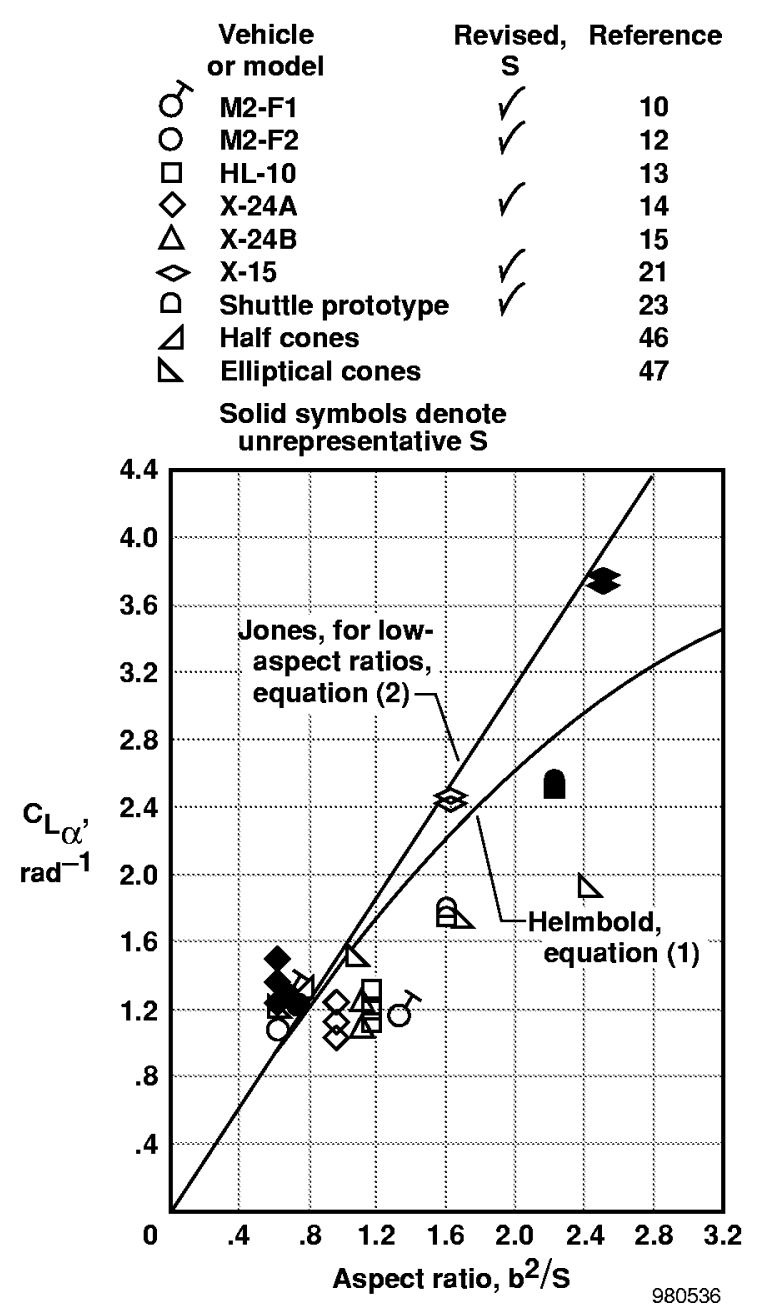

(a) Not adjusted for compressibility effects.

Figure 2. The relationship of lift-curve slope with aspect ratio as obtained in flight, from generic models and from theories of Jones and Helmbold (Krienes).
The lift-curve slopes for each of the flight vehicles were expected to occur below the Jones and Helmbold relationships, which represent maximum efficiency for medium- or low-aspect-ratio configurations that obtain their lift from circulation. However, the results from both $\mathrm{M} 2$ vehicles and the $\mathrm{X}-24 \mathrm{~A}$ vehicle, as shown by the solid symbols in figure 2(a), considerably exceed these expectations. In addition, the X-15 solid-symbol lift-curve slope greatly exceeds the Helmbold relationship. These comparisons of lift-curve slope data to the Jones and Helmbold expressions raise at least three questions:

- To what extent is reference area a factor that contributes to the apparent anomalies?

- Do very-low-aspect-ratio wind-tunnel model data exist that would support or refute the lifting-body slopes that exceed the Jones expression?

- To what extent are compressibility effects a factor contributing to the apparent anomalies?

These questions have been addressed, and some of the results are represented by the open symbols in figure 2(a). Representative reference areas have been assigned for five of the seven vehicles; the other two vehicles were already assigned representative reference areas, as published. The revised reference areas and the resulting lift-curve slopes are also shown in table 2 . Figure 2(a) also shows low-aspect-ratio wind-tunnel model results. ${ }^{46,47}$

The five vehicles for which reference areas were revised were those whose previously published reference areas did not accurately reflect the total planform area (projected onto the $x-y$ plane), but were simply the commonly accepted value in conventional use during the specific flight program. For the M2-F1 vehicle, the value of $S=139 \mathrm{ft}^{2}$ was formerly used, ${ }^{10}$ which was the planform area of the lifting body itself. However, the elevons that extend laterally beyond the body increase the span by approximately $4.7 \mathrm{ft}$ and represent $13.4 \mathrm{ft}^{2}$ of additional area. In order to qualitatively determine its contribution to the lift of the M2-F1 vehicle, the elevon planform area should be included in the reference area and accounted for in the definitions of force coefficients and aspect ratio. Similarly, for the M2-F2 and the X-24A data (the open symbols), actual projected planform areas as defined in references 12,48 , and 49 have been applied instead of the conventional program values that were used in references 12 and 14 .

As figure 2(a) shows for the M2-F2 vehicle, the revised data still show $C_{L_{\alpha}}$ greater than the 
relationships of Jones and Helmbold for low-aspect ratios. However, application of the revised (more representative) reference areas causes the data for the M2-F1 and the X-24A vehicles to fall below the theoretical relationships of equations (1) and (2). A literature search for the lifting characteristics of model shapes having aspect ratios less than 1.0 reveals that such elevated lift-curve slopes as shown for the M2-F2 vehicle may be expected. Results from wind-tunnel tests (shown in figure 2(a) as open right triangles) represent slender half-cones ${ }^{46}$ and elliptical cones. ${ }^{47}$

The reason that the M2-F2 vehicle and the slender shapes of references 46 and 47 (that is, those having aspect ratios less than 1.0 ) have relatively high lift-curve slopes may be related to well-developed forebody vortices caused by crossflow as reported by Allen and Perkins $^{29}$ and Hoerner. ${ }^{30-31}$ Because the model data of references 46 and 47 were untrimmed, their lift-curve slopes would be expected to be optimistic. The halfcones, having relatively sharp lateral edges, would be expected to produce vortex lift. However, the elliptical cone with the most slender planform (lowest aspect ratio) also has a relatively high slope compared to theory. Thus, the conjecture regarding well-developed vortices (resulting from body crossflow) providing an extra component of lift is afforded credence even if sharp lateral edges are absent.

Because of this evidence that crossflow (counterrotating vortex pair) effects may contribute significantly to the lift of the slender forebody portions of lifting bodies, considering that the forebodies of the $\mathrm{X}-15$ aircraft and the Shuttle prototype may likewise generate significant amounts of crossflow lift is appropriate. Therefore, for these winged vehicles, the forebody planform area and the wing area projected to the vehicle centerline will now be considered to be the reference area. ${ }^{* *}$ The consequences of the revised reference areas for the X-15 aircraft and Shuttle prototype are represented in figure 2 (a) by the respective open symbols.

The revisions of reference area and aspect ratio influence all vehicles except the HL-10 and X-24B vehicles, both of which already had proper reference areas as published. Note that a substantial reduction in lift-curve slope exists for the X-15 aircraft and Shuttle prototype in figure 2(a) when solid symbols are

\footnotetext{
${ }^{* * *}$ Planform area aft of the wing trailing edge will not be included as reference area in conformance with reference 27 , which postulates that for pointed shapes, "sections behind the section of maximum width develop no lift,"
}

compared with open symbols. Note also that when the area and span effects of the M2-F1 elevons are applied, the datum shifts to a much higher aspect ratio and below the Helmbold curve. In addition, as noted earlier, the $\mathrm{X}-24 \mathrm{~A}$ data are no longer greater than the theoretical curves.

As noted earlier, the lift-curve slope data from the half-cone models ${ }^{46}$ and the elliptical cone models ${ }^{47}$ tend to confirm the M2-F2 flight results, which exceed the Jones relationship. The values for the elliptical cones at aspect ratios greater than 1 , however, have lift-curve slopes that are significantly lower than both the Helmbold and Jones relationships (equations (1) and (2), respectively). For the elliptical cones having the highest aspect ratios (that is, clearly nonslender), a lift component due to circulation likely exists in addition to some degree of crossflow; whereas at the lowest aspect ratios, the crossflow component of lift is more dominant. $^{30,31}$

Regarding compressibility effects, table 2 shows that the lift-curve slope data obtained from the vehicles represent a range of subsonic Mach numbers. Compressibility effects may be at least approximately accounted for by applying the often-used PrandtlGlauert factor, $\left(1-M^{2}\right)^{0.5}$. Both Gothert ${ }^{50}$ and Hoerner $^{30}$ believe that for the lower aspect ratios, the exponent $n$ in $\left(1-M^{2}\right)^{n}$ should be less than 0.5 . Nevertheless, compressibility effects are approximated here by use of the more common exponent of 0.5 . Figure 2(b) shows the lift-curve slopes from figure 2(a) for the seven vehicles, based on the more representative reference area, adjusted for compressibility effects. The purpose here is to show that, for the vehicles having data at two Mach numbers (the M2-F2, X-24B, and the X-15 vehicles, and the Shuttle prototype), accounting for compressibility effects places the affected data somewhat in alignment with the relationships of equations (1) and (2).

A major factor that provides greater order for the data in figure 2(b), as compared to figure 2(a), was the application of the more representative reference areas. Adjustment of the data for compressibility effects had less influence. Together, these factors did not provide an impressive coalescence of the flight results; however, that casually chosen reference areas can confound understanding and result in misleading conclusions has been established. Also of interest, based on the M2-F2 data and the slender-body data from references 46 


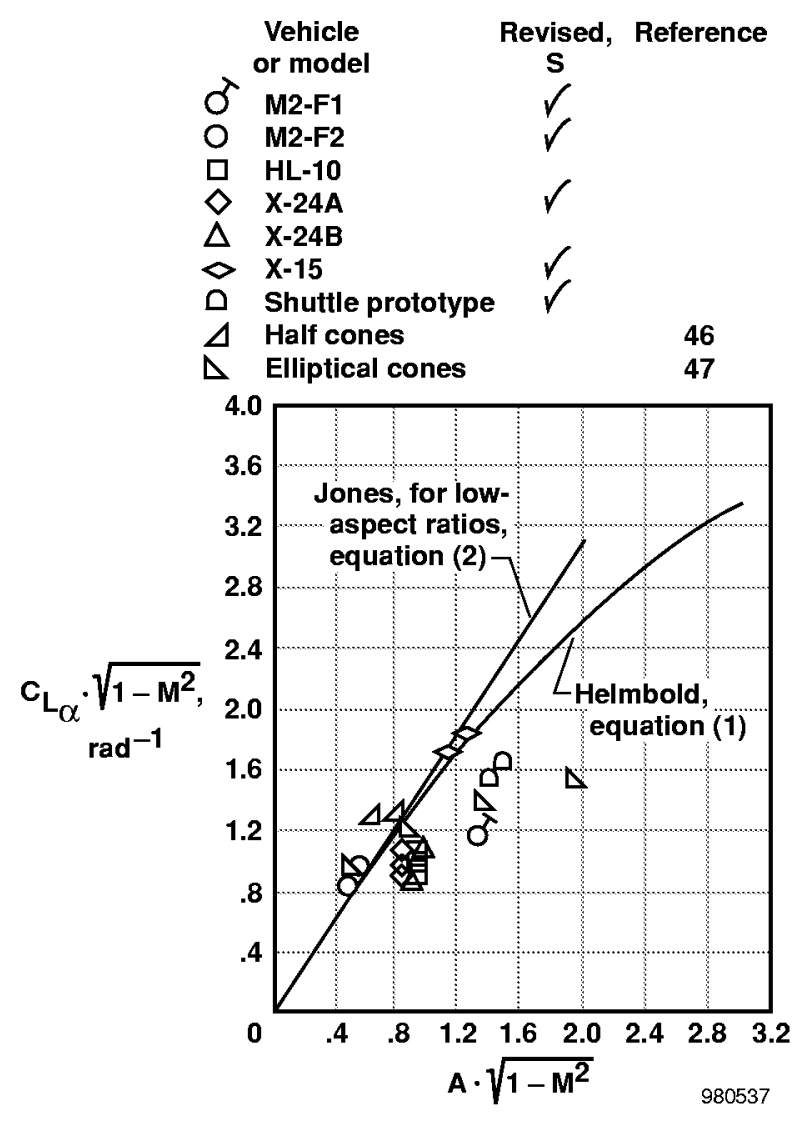

(b) Lift-curve slope and aspect-ratio values of figure 2(a) adjusted by applying revised reference areas and approximating for the effects of compressibility.

Figure 2. Concluded.

and 47 , is that a very-low-aspect-ratio lifting reentry vehicle may have a lift-curve slope somewhat greater than the Jones relationship. This possibility is also supported by data and reasoning contained in references 28-31.

At high- and moderate-aspect ratios, lift-curve slope is diminished by wing sweep. At aspect ratios less than 2, however, the influence of sweep on lift is weak. Figure 3, reproduced from reference 51, shows this characteristic. Consequently, wing-sweep effects for the $\mathrm{X}-15$ aircraft and the Shuttle prototype have not been addressed in this discussion of lift-curve slope.

\section{Lift-Related Drag}

The data array of lift-related drag characteristics for the subject vehicles uses a format employed by Hoerner in chapter 7 of reference 31 . Figure 4 shows these data

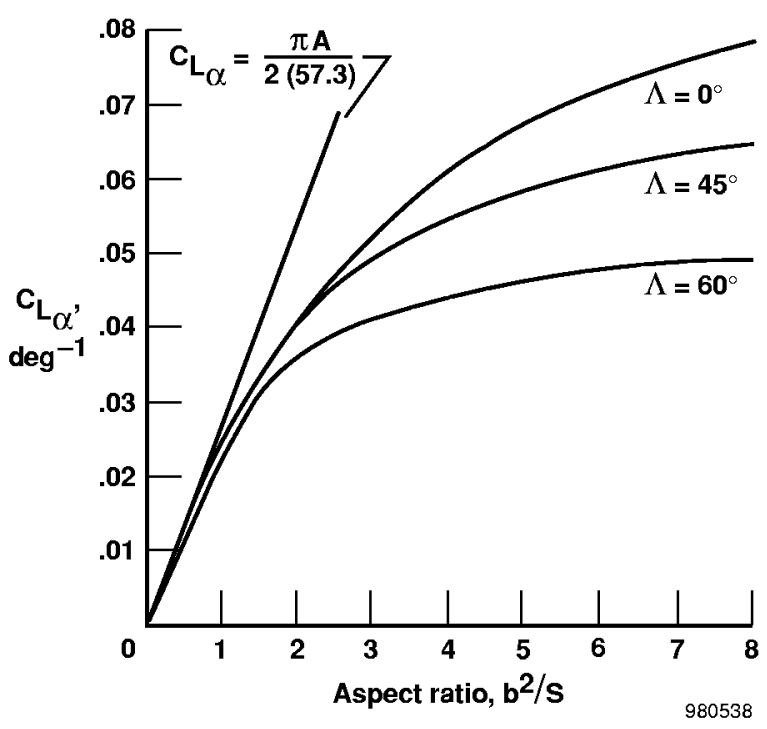

Figure 3. Variation of lift-curve slope with aspect ratio for various values of sweep. ${ }^{51}$

as drag-due-to-lift factor $\left(\Delta C_{D} / \Delta C_{L}{ }^{2}\right)$ plotted as a function of the reciprocal of aspect ratio $(1 / A)$. Included as a reference framework is a family of lines representing the theoretical relationship for an ideal elliptical span loading, wherein $\varepsilon=1.0$, and for significantly less optimum load distributions represented by $\varepsilon<1.0,31,32$ which are expected for the vehicles reported here.

The derivation of drag-due-to-lift factor and liftingefficiency factor would normally consist of obtaining $\left(\Delta C_{D} / \Delta C_{L}{ }^{2}\right)$ from their linear relationship and deriving $\varepsilon$ from Oswald's equation for a polar plot of $C_{L}$ as a function of $C_{D}$ in which the minimum drag is at zero lift. However, for several of the subject vehicles, the minimum drag did not occur at zero lift. For these vehicles, their polars were displaced, and $C_{D_{\min }}$ occurred at some finite lift coefficient defined as $C_{L_{\min }}$, which is the lift coefficient at the vertex of the parabolic, or nearly parabolic, polar. In reference 33 , a transformation is proposed by Wendt that accounts for the displacement of the vertex; for polars of this type, equation (3) is used for defining lifting efficiency.

Application of Wendt's transformation should be straightforward enough; however, for some low-aspectratio vehicles, analysis of the available flight data still presents a challenge. Low-aspect-ratio vehicles often 
have polars that are quite shallow-that is, the vertex, where minimum drag coefficient occurs on the parabolic curve, is not as sharply defined as it is for somewhat higher aspect-ratio aircraft. In addition, for some of the polars in this study, the curve is incomplete and whether the lift coefficient for the vertex has been reached is not readily apparent; or for some, the vertex is judged to not have been defined by the range of the data. For all of these cases herein, the authors' judgement has been exercised and equation (3) has been applied. Figure 4 shows the results of this approach. The $\varepsilon$ factors thereby derived are tabulated in the legend of the figure and are also evident by the relative positions of the data points (of $\Delta C_{D} / \Delta C_{L}{ }^{2}$ from table 3) in the plot with respect to the theoretical reference lines.

Figure 4 shows a dashed line intersecting the ordinate at approximately 0.16 that represents a drag increment, separate and above the induced drag associated with the induced angle of attack. Note that this line is parallel and therefore, where applicable, is additive to the line corresponding to $\varepsilon=1.0$. This increment is defined as $1 / 2 \pi$; and according to reference 31 , the additional drag is analogous to that resulting from the loss of leading-edge suction and the associated losses from flow separation and reattachment. For lifting bodies, the analogy may involve drag associated with the flow separation over the upper body caused by crossflow as well as the lack of a prominent leading edge. Note that only the winged vehicles, the X-15 aircraft and Shuttle prototype, have drag-due-to-lift factors below this line, although one configuration of the $\mathrm{X}-24 \mathrm{~A}$ vehicle is "borderline." Figure 4 shows a qualitative interpretation of the relative lifting efficiency of the subject vehicles. All slopes of $\Delta C_{D} / \Delta C_{L}{ }^{2}$ shown in figure 4 and in table 3 are based on the revised reference areas used and discussed in the "Lift-Curve Slope" section (table 2). The lifting-efficiency factor, $\varepsilon$, is not influenced by the choice of reference area.

\section{Maximum Lift-to-Drag Ratio}

Figure 5 shows maximum lift-to-drag ratio as a function of the ratio of span-squared to wetted area for each of the vehicles in subsonic flight. This format is commonly used by designers of conventional subsonic aircraft because at subsonic speeds, air vehicle efficiency is most directly influenced by span and wetted area. Raymer ${ }^{34}$ refers to this abscissa function as the "wetted aspect ratio."

For the lifting bodies, the X-15 aircraft, and the Shuttle prototype, all of which have significant amounts of base drag, recognizing the "base" effects by assigning base drag to the previously mentioned equivalent skin friction coefficient parameter, $C_{F_{e}}$, is necessary. Consequently, figure 5 also shows a reference framework consisting of a family of constant values of $C_{F_{e}}$ as employed by reference 35 . This family of curves is derived from the often-used expression that relates

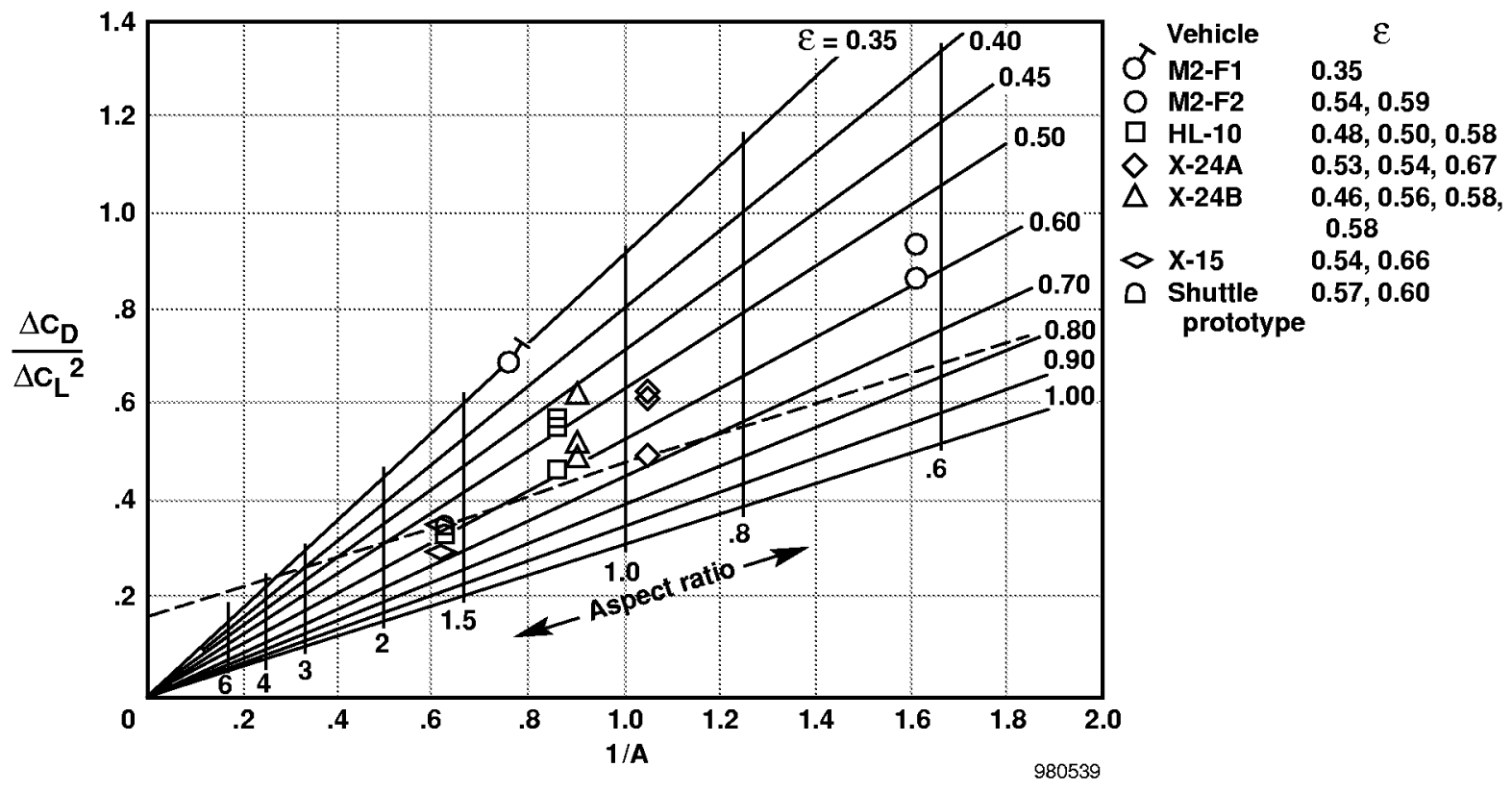

Figure 4. The relationship of drag-due-to-lift factor with the reciprocal of aspect ratio. 


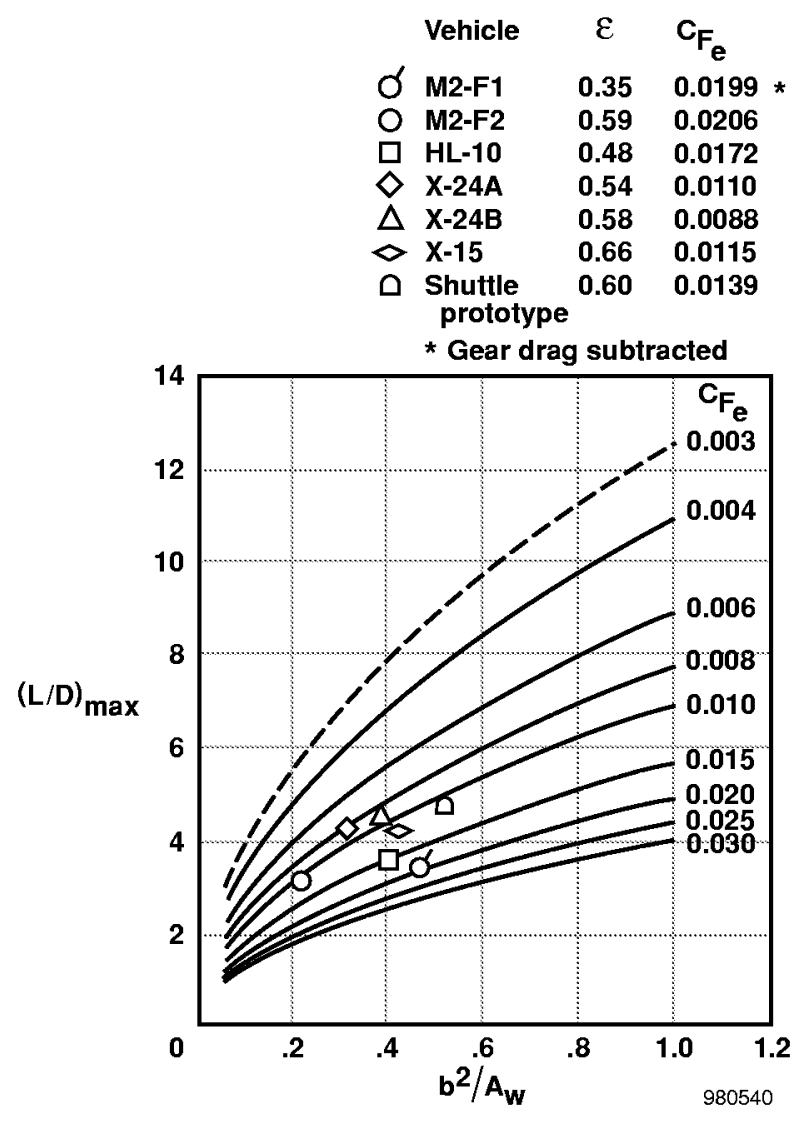

Figure 5. The relationship of the maximum lift-to-drag ratio to wetted aspect ratio.

maximum lift-to-drag ratio to the minimum drag coefficient (here expressed as $C_{F_{e}}$ ), aspect ratio, and the lifting-efficiency factor (equation (6)). The range of the family of $C_{F_{e}}$ curves shown in figure 5 covers the range of values experienced by the vehicles. Thus, the format used will accommodate this class of vehicles whose minimum drag consists of a large component of base drag as well as friction drag. A lifting-efficiency factor, $\varepsilon$, of 0.6 was assigned to these curves because this value is approximately the average for the subject vehicles as a group. The dashed curve for the equivalent skin friction coefficient is included because it represents a nominally clean modern aircraft that does not have a truncated body.

All M2-F1 lift and drag data were obtained "as flown," with gear exposed. The value shown in figure 5 is adjusted for "retracted" gear, based on the estimated gear drag increment obtained from reference 10 . The discussion that follows applies to the highest values of maximum lift-to-drag ratio obtained for each vehicle. Although figure 5 shows the highest values for each vehicle, table 3 includes maximum lift-to-drag ratios for each vehicle for less efficient control deflections or conditions as well.

The highest values of maximum lift-to-drag ratio for five of the vehicles and their collective relationship to the reference framework of curves form an array (a band of $(L / D)_{\max }$ over a range of $\left.b^{2} / A_{w}\right)$ that should be a useful reference source with which to relate future reentry-type vehicles. The M2-F1 and HL-10 lifting bodies, which are less efficient, should be no less useful to the degree their lesser apparent efficiency is understood. In the case of the M2-F1 vehicle, the outboard elevons would again seem to be negative components in this data format because they add drag, are inefficient in providing lift (and were not intended to provide lift), and displace the datum to a higher $b^{2} / A_{w}$ value of the abscissa by a factor of approximately 2 . The HL-10 lifting efficiency, $\varepsilon$, is somewhat low, and its equivalent skin friction parameter, $C_{F_{e}}$, is quite high, although the HL-10 has a relatively modest component of base drag for the subsonic control position configuration.

Assigning the derived base pressures to the projected area of all body surfaces normal to the flight path does not account for the flight-determined value of $C_{F_{e}}$ for the HL-10 vehicle. This value suggests that if all aft sloping surfaces experienced separated flow, the resulting drag would not produce the observed equivalent friction drag coefficient. Therefore, considering compressibility effects, trim drag, and outboard fin drag due to sideloads as possible contributors to the high $C_{F_{e}}$ values for the $\mathrm{HL}-10$ vehicle at $C_{D_{\min }}$ conditions is reasonable. Some combination of these factors plus some separated flow over the aft sloping surfaces of the upper body is speculated to cause the HL-10 maximum lift-to-drag ratio to be displaced somewhat below the aforementioned band represented by the M2-F2, X-24A, $\mathrm{X}-24 \mathrm{~B}$, and $\mathrm{X}-15$ vehicles and Shuttle prototype in figure 5 .

The lower maximum lift-to-drag ratios for the HL-10, $\mathrm{X}-24 \mathrm{~A}$, and $\mathrm{X}-24 \mathrm{~B}$ vehicles that are listed in table 3 represent the effects of increased longitudinal control 


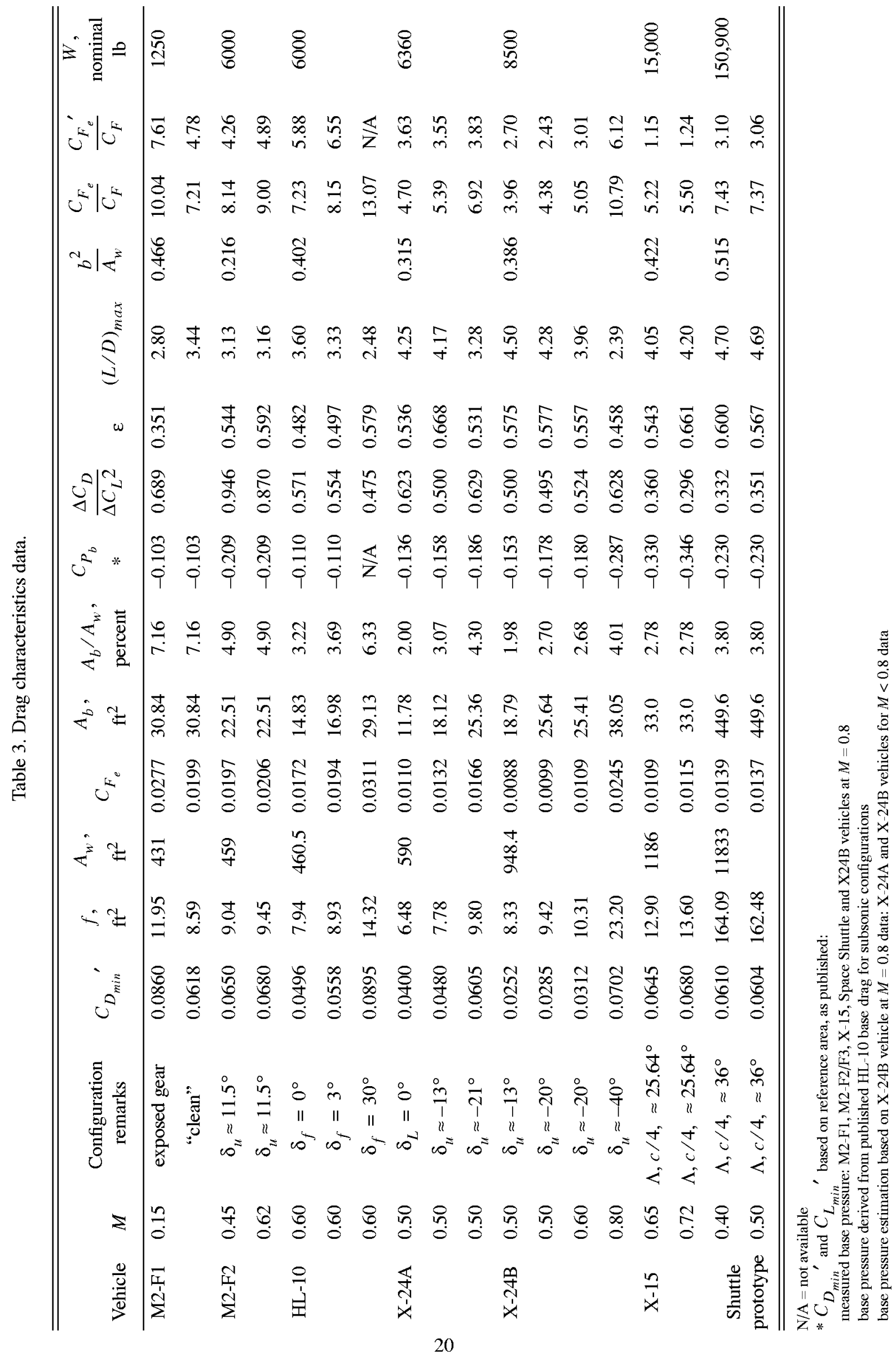


deflections (that is, larger wedge angles). The lowest values of maximum lift-to-drag ratio for the HL-10 and the $\mathrm{X}-24 \mathrm{~B}$ vehicles represent the large wedge angles used when traversing the transonic region. The lowest value for the M2-F1 vehicle (also less than 3) was measured for this vehicle with exposed landing gear.

\section{Minimum Drag}

Minimum drag is presented in several formats in order to better understand which components are dominant and to reveal the relationship of forebody and base drag. The metrics used, as defined earlier, include equivalent skin friction coefficient $\left(C_{F_{e}}\right)$ and equivalent parasite drag area $(f)$; as previously mentioned, these forms of minimum drag include both base and forebody drag. Base drag is defined for each vehicle (using measurements for five of the vehicles and estimates for the other two) to allow separation of base drag and forebody drag components. The data from the vehicles are presented collectively in tabular and graphic formats in order to provide a greater understanding than would likely be achieved by studying the vehicles individually.
Table 3 shows the basic data along with some of the significant physical characteristics of the vehicles. The minimum drag coefficients are tabulated as derived using the reference areas published by the respective reference authors. Although the revised reference areas are believed to be a rational improvement over the areas that they replace (as noted in the section on "Lift-Curve Slope"), the format chosen here for graphically presenting the minimum drag will eliminate the conventional reference area as a factor. Perkins and Hage, ${ }^{37}$ and subsequently others, have avoided the concern about reference area definition by multiplying the minimum drag coefficient by the reference area to define an equivalent parasite drag area, $f$, as shown in equation (7).

Figure 6 shows the equivalent parasite drag area for each of the subject vehicles as a function of total wetted area. Table 3 shows the range of equivalent parasite drag area for the subject vehicles is quite large, from $6.5 \mathrm{ft}^{2}$ to $164 \mathrm{ft}^{2}$. Total wetted area for each vehicle is defined as all outer mold-line or external surface areas ahead of a blunt base or any trailing edge. Thus, the definition

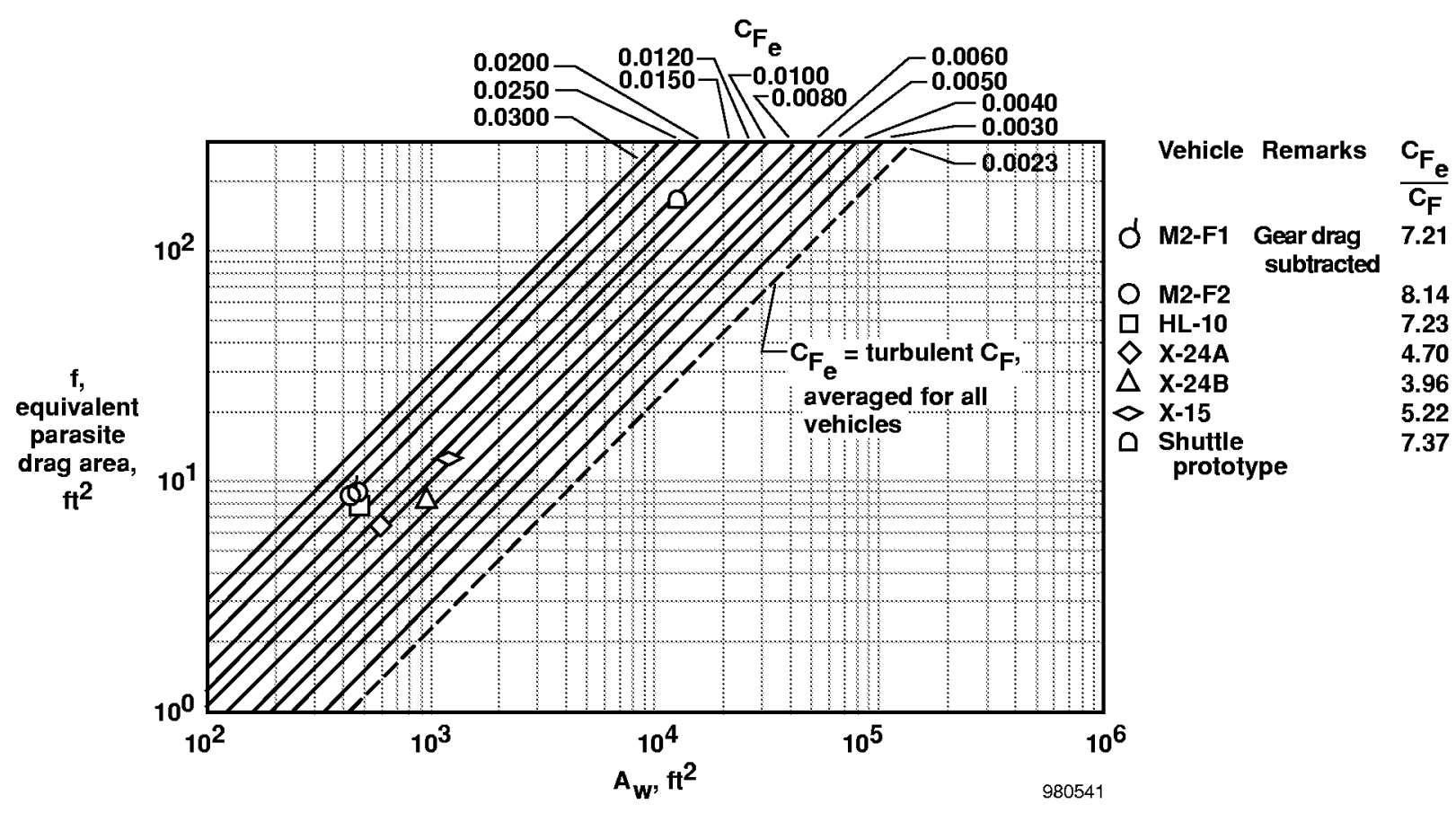

Figure 6. The relationship of equivalent parasite drag area and equivalent skin friction coefficient to total wetted area, at subsonic speeds. 
assumes that the flow is attached over these surfaces. Separated regions ahead of the base, vortex flow ahead of the base, and negative base pressure coefficients each represent drag increments in excess of the viscous drag generated by the actual wetted surfaces. Hence, this drag metric defines the sum of the drag sources (excluding lift) that include friction drag for turbulent flow conditions as well as drag components in excess of friction. Because even an ideal body will have friction drag, this metric is labeled as a "parasite" factor because the metric includes such parasitic losses.

The equivalent parasite drag area can also be interpreted in terms of an equivalent skin friction coefficient, $C_{F}$, by noting the location of a datum point for a given vehicle relative to the family of constant equivalent skin friction lines (fig. 6). The equivalent skin friction coefficient is, of course, another metric that reveals the degree to which measured minimum drag of a vehicle exceeds the ideal minimum drag (that is, the skin friction drag over the wetted area). The average skin friction coefficient over wetted areas for all seven vehicles, assuming flat-plate, turbulent, boundary-layer flow (adjusted by a form factor of 1.02) at flight Mach and Reynolds numbers, is $C_{F}=0.0023$, which can also be considered as a reference value of $C_{F_{e}}$ (see the dashed line in figure 6). Table 3 shows the explicit values of equivalent skin friction coefficient for each of the subject vehicles at each flight condition considered herein. These values result from equation (5), as shown in the "Methods of Analysis" section.

Although table 3 shows more than one value of $f$ or $C_{F_{e}}$ for most of the vehicles, figure 6 shows only the lowest value for each vehicle. For some of the vehicles, drag coefficients exist that represent both the subsonic control configuration (the value shown in figure 6) and the less-efficient transonic configuration that requires larger control deflections. For the X-15 aircraft, the $C_{F}$ included in figure 6 is the one for the lower Mach number, and thus is the one experiencing lower compressibility effects. In the case of the M2-F1 lifting body, which had a fixed landing gear, the estimated landing gear drag has been subtracted for the datum of figure 6. This estimate is from reference 10 and was based on information obtained from Hoerner. ${ }^{31}$ All data in figure 6 include the base drag for each vehicle.
A cursory summary of the data shown in figure 6 can be stated as follows:

- The early generations of lifting bodies, the M2 and the HL-10 vehicles, have equivalent skin friction coefficients between 0.017 and 0.020 (in contrast to the average value of skin friction for all seven vehicles for turbulent flow, 0.0023).

- For the X-24A and X-15 vehicles, the corresponding coefficients are approximately 0.011 .

- The X-24B vehicle, the last of the lifting bodies, had a coefficient slightly less than 0.009 .

- The wetted surfaces of the Shuttle prototype Enterprise were purposely roughened to simulate the thermal protection tiles of operational vehicles to follow. In addition, this vehicle had a very large base area. Consequently, the Shuttle prototype equivalent friction coefficient of approximately 0.014 is understandably higher than the three lowest values, and occupies the median position in the array of coefficients for the subject vehicles.

Note that the range of the lowest equivalent skin friction coefficients for each of the seven vehicles, from approximately 0.009 to 0.020 , is from 4 to slightly more than 8 times the skin friction drag that would occur from an attached, turbulent, boundary layer alone. This range in equivalent skin friction is essentially the same as the range of values for older propeller-driven aircraft having fixed landing gears. ${ }^{52}$ In the case of the seven vehicles, this range would be the base drag increment and upstream vortices not associated with the base, possible compressibility effects, and local regions of separated flow that largely correspond to the drag penalties associated with exposed landing gears and the propulsion system (including cooling losses) for the small, more conventional aircraft. Figure 6 also shows in tabular form values of $C_{F_{e}} / C_{F}$ for each data symbol on the graph, where $C_{F}$, the theoretical skin friction for turbulent flow at the flight condition of each vehicle, is calculated by the methods of reference 38 and augmented by the form factor of 1.02 from reference 39 . Table 3 shows corresponding values of this ratio for every flight condition considered.

The preceding discussion revealed that the lowest of the equivalent skin friction coefficients among the several vehicles was approximately 4 times greater than 
the associated turbulent boundary-layer skin friction coefficient. As noted, when relating the equivalent skin friction coefficients of the subject vehicles to that of propeller-driven aircraft having exposed landing gear, significant drag penalties exist in addition to the friction and base drag components, even at minimum drag conditions. These additional losses are designated as excess equivalent skin friction or as excess drag.

A family of relationships can be assembled representing the approximate level of equivalent skin friction coefficient $\left(C_{F_{e}}\right)$ corresponding to basic skin friction for turbulent flow over the forebody, variations in base pressure coefficient, and the ratio of base area to wetted area for the subject class of vehicles. Compared with measured data, this format should provide some understanding of how much the equivalent skin friction coefficients for the subject vehicles exceed calculated levels based on friction drag for turbulent flow plus measured and estimated base pressures.

Figure 7 shows this comparison, where the family of lines is calculated from equation (10) over a range of constant base pressure coefficients. All of the lines start at the reference average $C_{F_{e}}$ value of $C_{F}=0.0023$, such that each line represents a calculated level of $C_{F_{e}}$ with basic skin friction drag and base drag for a specific value of $A_{b} / A_{w}$.

For the subject vehicles considered in this report, a vehicle-specific value of $C_{F}$ can be calculated using vehicle-specific $C_{P_{b}}$ data ${ }^{\dagger}$ (positioned as appropriate within the family of constant $C_{P_{b}}$ lines) and vehiclespecific $C_{F}$ values (instead of the average value of 0.0023 ). These values are represented by the smaller symbol of each symbol pair, located at the lower end of the vertical line that connects to the corresponding larger symbol at the upper end.

When the smaller symbols are interpreted with respect to the ordinate scale, they approximate the equivalent skin friction coefficient each subject vehicle should have if the vehicle experiences drag only from the friction resulting from a fully attached, turbulent boundary layer over the wetted surface and the base

\footnotetext{
Tupper and lower flap deflections necessary for calculating base area for the $\mathrm{X}-24 \mathrm{~A}$ and $\mathrm{X}-24 \mathrm{~B}$ vehicles were obtained from references 53 and 54, respectively.
}

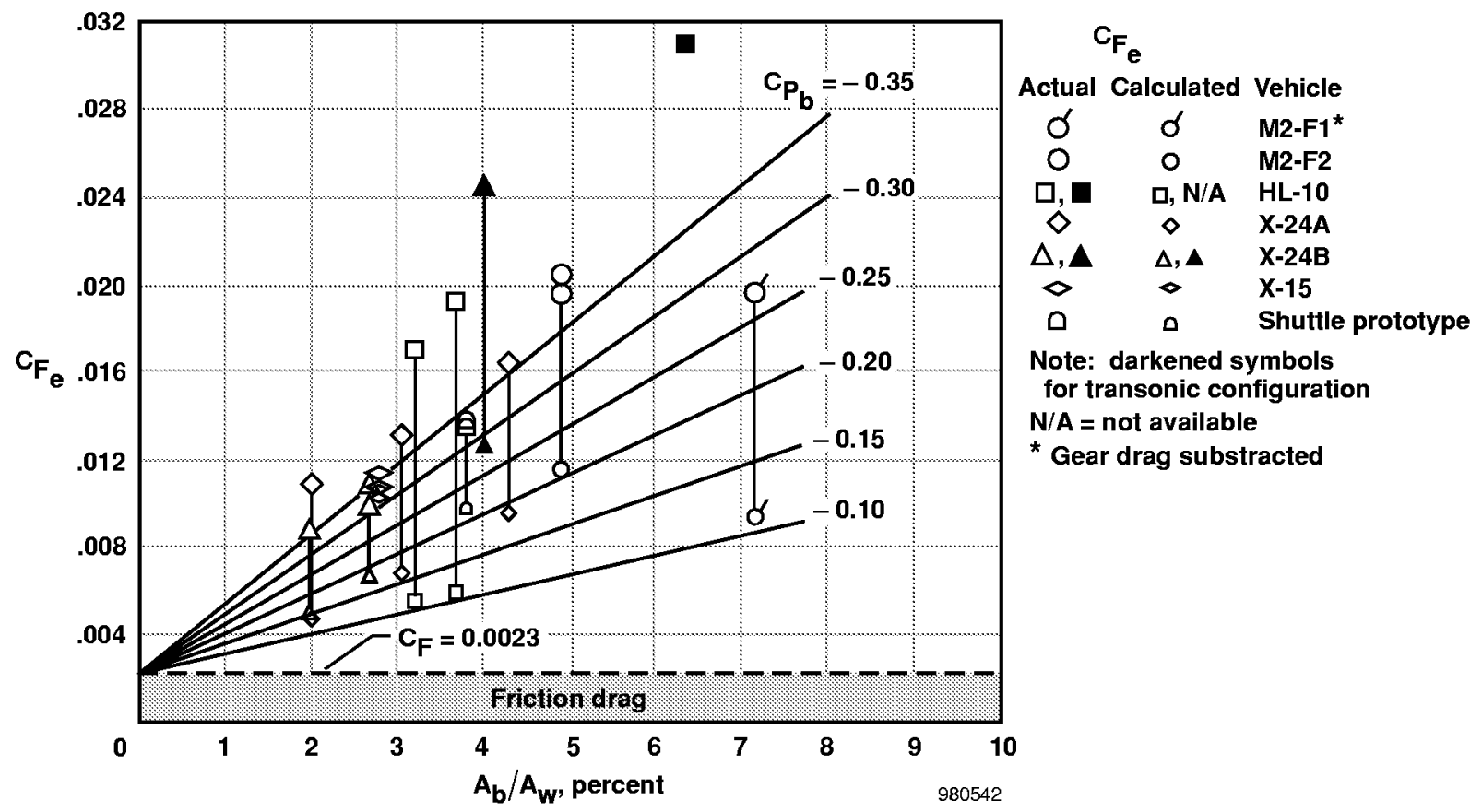

Figure 7. The relationship of equivalent skin friction coefficient to the ratio of base-area-to-wetted-area. 
drag associated with the pressure coefficients indicated in table 3. The larger symbol at the upper end of a given vertical line is the experimentally measured value of $C_{F e}$ for that vehicle as obtained from table 3 . The increment of $C_{F_{e}}$ represented by the length of the vertical line segment connecting a symbol pair quantifies the excess drag (that is, the amount that the actual drag exceeds the presumed or calculated drag at these minimum drag conditions). The authors speculate that the excess drag increments result from:

- local regions of separated flow upstream of base stations or any trailing edges.

- vortices generated by deflected control surfaces, body crossflow, and in some cases, unproductive side loads generated by outboard vertical or canted fins.

- roughness and protuberance effects.

- compressibility effects.

- data uncertainty (see the "Data Uncertainty" section).

For example, note the M2-F2 lifting body (the circular symbol without a flag), which has a base-areato-wetted-area ratio of 4.9 percent. If no excess drag sources existed for this vehicle, its calculated level of $C_{F_{e}}$, associated with the measured base pressure coefficient of -0.209 plus friction drag, would be 0.0117. However, the actual level of $C_{F}$ for the M2-F2 vehicle, (the larger circular symbols) is approximately 0.020. Apparently, this vehicle experiences significant excess drag beyond the skin friction and base drag, even at minimum drag conditions. The M2-F1 and HL-10 vehicles experience even larger excess drag.

The X-24B lifting-body vehicle is represented by the triangular symbols. Unfortunately, base pressure measurements were made for this vehicle only in the transonic configuration, wherein the very large upper and lower flap deflections created a flared afterbody. 55 The sum of the upper and lower flap deflections was approximately $68^{\circ}$; refer to the schematic of body-flap angles in Figure 1(i). These data (the darkened triangle symbols) were obtained at a Mach number of 0.8 , whereas the other X-24B data presented in this paper were obtained at Mach 0.5 and Mach 0.6 with smaller flap deflections. The very large excess drag increment noted between the large and small darkened triangular symbols shows the obvious effects of compressibility and of the large flare angles that produce higher drag from both the windward surface and from reduced pressure on the leeward side. ${ }^{56}$

This result, obtained at Mach 0.8 , is included with the other data representing lower Mach numbers because it provides a base pressure coefficient reference datum that is used for estimating base pressure coefficients for the $\mathrm{X}-24 \mathrm{~A}$ and the other $\mathrm{X}-24 \mathrm{~B}$ data pairs. The major portion of the base region for these two vehicles is the same; and the upper and lower body flaps, which influence the base area as they are deflected, are identical. Note that the $\mathrm{X}-24 \mathrm{~B}$ vehicle had a very large increment of excess drag for the transonic configuration (the darkened triangles) as would be expected; however, the X-24B subsonic configurations experienced excess drag increments much smaller than those for the other lifting bodies. The excess drag of the X-24A vehicle, at low lift, is somewhat larger than that of the subsonic $\mathrm{X}-24 \mathrm{~B}$ vehicle, but is still much smaller than those of the earlier lifting-body configurations (the M2-F1, M2-F2, and HL-10 vehicles).

The excess low-lift drag increment for the X-15 aircraft is very small. The likely reason for this small increment is the relatively high-fineness ratio of the fuselage, thin wings, and horizontal stabilizer, which allows for small-angle aft-sloping surfaces. Therefore, these surfaces maintain a proverse pressure gradient that assures attached flow. These features virtually eliminated compressibility effects.

Because the Shuttle prototype Enterprise had a roughened surface to simulate the thermal protection systems of the actual orbiting Space Shuttles to follow, the value of $C_{F}$ used to determine the position of the smaller symbol for the Shuttle prototype (fig. 7) is too low for this vehicle. Consequently, the excess drag increment shown for the Shuttle prototype in figure 7 is too large, but the magnitude of this discrepancy cannot be quantified based on the presently available data.

\section{Base Pressure Coefficients}

Hoemer compiled base pressure data from projectiles, fuselage shapes, and other small-scale threedimensional shapes ${ }^{31}$ and derived therefrom an equation

\footnotetext{
According to reference 57, preflight estimates of thermal protection system drag indicated an additional increment of 0.00084 (based on wetted area) to the Shuttle friction drag. However, reference 57 also considered the estimate of thermal protection system drag to be too large after examining postflight data from an orbiting Space Shuttle (Columbia, mission STS-2).
} 
that related the base drag and base pressure coefficients to the forebody drag of the respective bodies (eq. (14)). Reference 31 also includes an equation that describes the analogous relationship for quasi-two-dimensional shapes that shed vortices in a periodic manner, the wellknown Kármán vortex street (eq. (15)). Base pressure data from some of the subject vehicles will be compared on the basis of the Hoerner relationships and modifications to his equations (using different $K$ values). The search for flight-measured base pressure data for the seven subject vehicles is somewhat disappointing, considering that each of these vehicles has a significant component of base drag. Table 4 shows the results of the literature search.

Note that the M2-F3 vehicle is virtually the same as the M2-F2 vehicle. All configurational dimensions are the same except that a centerline upper vertical fin was added to the M2-F3 vehicle. For this reason, the unpublished base pressure data from the M2-F3 lifting body are accepted as representative of those of the M2-F2 lifting body. Consequently, the M2-F2 and the M2-F3 lifting bodies will be treated as if they were the same vehicle in the analysis to follow.

Because of Hoerner's convincing demonstration that base pressure is related to forebody drag, comparing the available base pressure coefficients from the subject vehicles to his equations is possible. Figure 8 shows these comparisons. Figure 8 also includes a shaded band for Hoerner's three-dimensional equation that is bounded by numerator coefficients, $K$, of 0.09 and 0.10 . By modifying Hoerner's original equation with these $K$ coefficients, the base pressure coefficients from the $\mathrm{X}-15$, the M2-F3, and the Space Shuttle vehicles (which are obviously three-dimensional) are observed to fall within or relatively close to this band.

Figure 8 also shows that the flight data are relatively close to Hoerner's quasi-two-dimensional relationship (eq. (15)). The relatively higher (more negative) pressure coefficient from the X-24B vehicle (dark triangle) is caused by the large wedge angle, ahead of the base, formed by the upper and lower flaps that are used for control in pitch. The upper flap was deflected upward approximately $40^{\circ}$, and the lower flap was deflected downward approximately $28^{\circ}$. This geometry is known to produce more negative base pressure coefficients. ${ }^{56}$ The only base pressure data from the $\mathrm{X}-24 \mathrm{~B}$ vehicle $^{55}$ were unfortunately obtained with a significantly larger wedge angle than existed for the subsonic control configurations. The X-24B polars for Mach 0.5 and Mach 0.6 were obtained using much smaller wedge angles.

The M2-F1 datum is unrepresentative of the subject class of vehicles in that the base region was pressurized to some extent by turning vanes (one on each side, below the rudders). Based on the available flight data, the vehicles considered herein (excepting the M2-F1 and the $\mathrm{X}-24 \mathrm{~B}$ vehicles) are best represented by the three-dimensional equation where $K=0.09-0.10$, which means base drag of blunt-based large-scale vehicles is higher than predicted by Hoerner's original three-dimensional equation. Based on evidence from references 40 and 59 and figure 8, subsonic flow separating from a relatively large, sharp-edged threedimensional base can be argued to exhibit quasi-twodimensional characteristics. In either case, the data indicate more negative base pressure coefficients than

Table 4. Base pressure sources

\begin{tabular}{|c|c|c|c|}
\hline Vehicle & $C_{P_{b}}$ data & $\begin{array}{l}\text { Reference } \\
\text { number }\end{array}$ & Remarks \\
\hline M2-F1 & Yes & 10 & The base region was pressurized by turning the vanes. \\
\hline M2-F3 & Yes & Unpublished & The M2-F3 data were applied to the M2-F2 vehicle. \\
\hline $\mathrm{HL}-10$ & No & & The base drag data exist, but no explicit base pressure data exists. \\
\hline $\mathrm{X}-24 \mathrm{~A}$ & No & & Base pressure coefficients were estimated using X-24B results. \\
\hline$X-24 B$ & Yes & 55 & $\begin{array}{l}\text { Base pressure coefficients for Mach } 0.5 \text { and Mach } 0.6 \text { were } \\
\text { estimated using Mach } 0.8 \text { results. }\end{array}$ \\
\hline $\mathrm{X}-15$ & Yes & 40 & \\
\hline Space Shuttle & Yes & 58 & \\
\hline
\end{tabular}




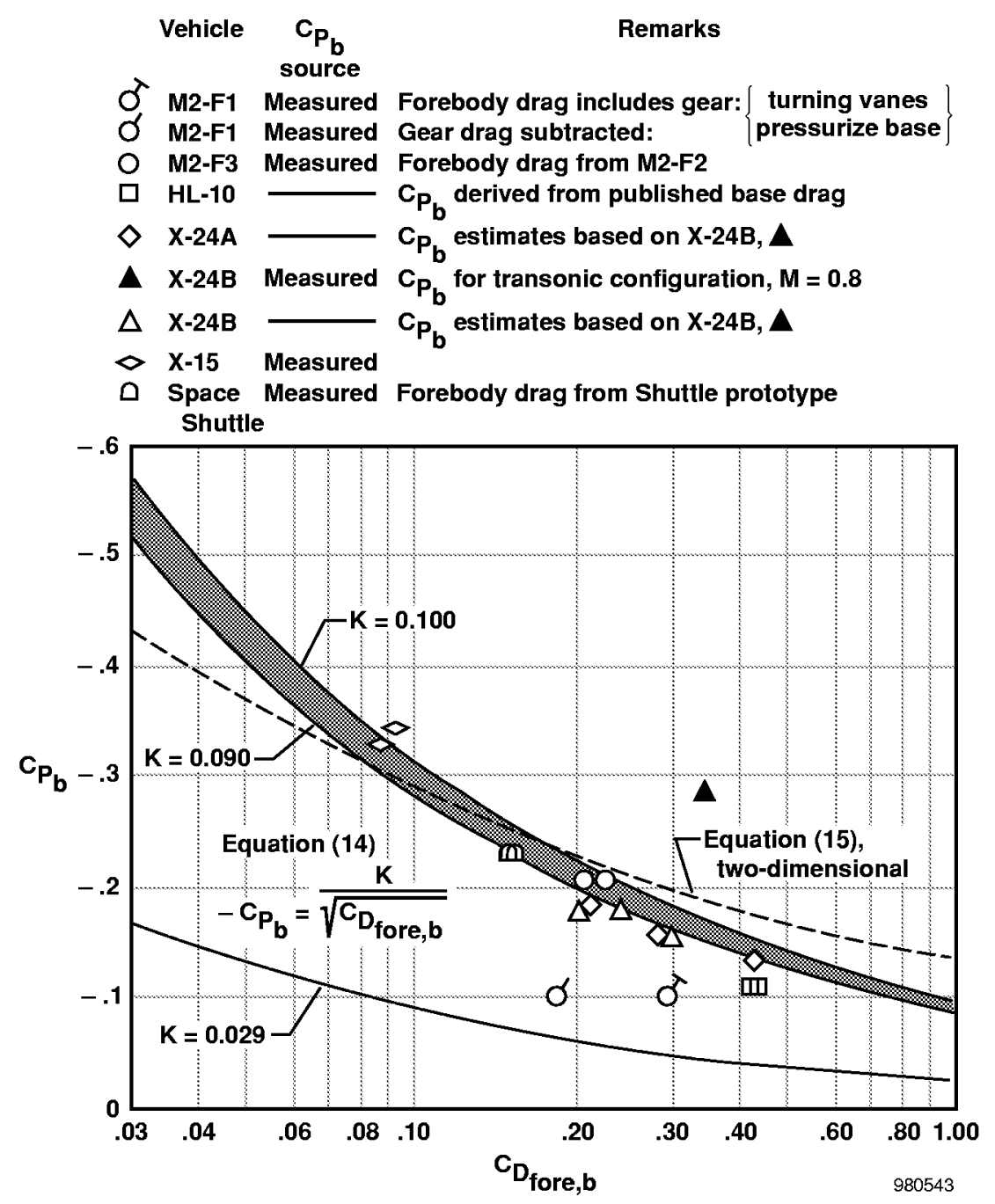

Figure 8. Comparison of base pressure coefficients for subject vehicles with Hoerners' two-dimensional relationship and with revised three-dimensional equation.

the unmodified three-dimensional equation ( $K=0.029$ ) would predict. Because of the large base drag component these base pressures represent, employing a method of pressurizing the base region may be advisable. Such methods are available, although their use necessarily complicates the afterbody design details. Considering the very large losses caused by the base region for this class of vehicles, such pressurizing devices deserve attention. ${ }^{31,60-66}$

\section{Optimum Minimum Drag}

Excluding the base pressure data from the M2-F1 and the $\mathrm{X}-24 \mathrm{~B}$ vehicles for the reasons already given, the data from the other three vehicles (M2-F3, X-15, and Space Shuttle vehicles) are believed to represent the generic blunt-based class of vehicles. More large-scale base pressure and overall minimum drag (and hence forebody drag) data must be obtained in flight to convincingly demonstrate their relationship. Defining this relationship for three or four values of forebody drag for the same outer mold-line shape would be most helpful. Until more flight data are obtained or a superior relationship is developed, the shaded region of figure 8 , derived from the data of the latter three vehicles, is assumed to be a reasonable representation of the base pressure characteristics for this class of reentry craft. Therefore, a revised version of Hoerner's threedimensional equation, $K=0.10$, has been used to show the dependence of minimum drag on the relative size of the blunt base over a significant range of 
forebody drag. Figure 9 shows this illustration, where each of four curves shows how overall minimum drag coefficient varies with forebody drag coefficient for discrete ratios of base area to wetted area $(2.5,5.0,7.5$, and 10 percent). The salient feature of these curves is that each has an optimum region of lowest overall minimum drag coefficient, $C_{F_{e}}$.

Note that for the 2.5-percent relationship, an optimum region (a drag "bucket") exists near the forebody drag coefficient value of 0.003 . Because these coefficients are based upon the wetted area, and because the smooth skin turbulent friction coefficient for these Reynolds numbers (in the $10^{7}$ to $10^{8}$ range) would be close to 0.002 , a configuration having a base-area-to-wetted-area relationship of 2.5 percent can afford only a minute amount of roughness, protuberance, or separation drag over the forebody if the optimum $C_{F_{e}}$ is to be achieved. Conversely, for the higher base-area-to-wetted-area relationships, which more closely represent many reentry configurations, the optimum $C_{F}$ (or drag bucket) occurs at significantly higher values of forebody drag coefficient, $C_{F_{e}}{ }^{\prime}$.

This characteristic should be of particular interest with regard to some emerging reusable launch vehicles that have relatively large base-area-to-wetted-area ratios (between 7.5 percent and 10 percent). This observation, of course, means that such configurations can afford (in fact, may benefit from) additional forebody drag in addition to the unavoidable smooth skin turbulent friction. Thus, surface roughness that may accompany a thermal protection system may actually provide a reduction in overall $C_{F_{e}}$ while increasing the forebody drag, providing the upper body is flat enough to maintain attached, high-energy flow.

Such a reduction would be the result of forebody roughness affecting the growth of the boundary layer from the nose to the edge of the base, which in turn affects the level of "vacuum" or suction at the base through a "jet-pump mechanism" as described by Hoerner. ${ }^{31}$ Thus, subject to the curves of figures 8 and 9 , forebody roughness adds to the thickness of the boundary layer, thereby reducing the pumping (vacuuming) of the base and reducing the base drag. The drag bucket curves of figure 9 are related to those seen in chapters 6 and 13 of reference 31 for bodies, nacelles, canopies, and airfoils.

Figure 9 shows the relationship of $C_{F}$ to forebody drag coefficient for the same vehicles as were

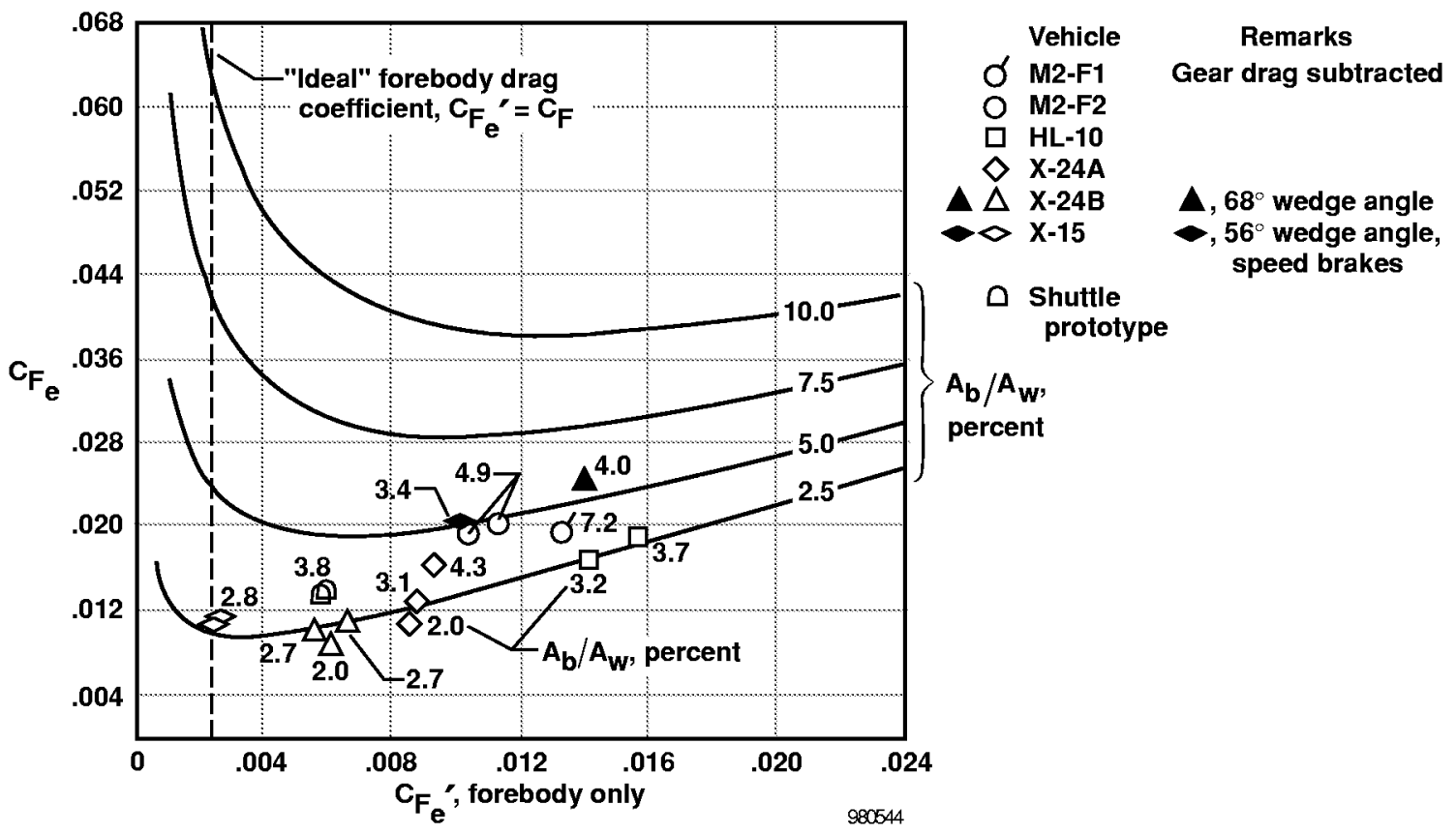

Figure 9. The relationship of equivalent skin friction coefficients for the complete vehicle and the forebody. 
represented in figure 8 . The numbers adjacent to each data symbol indicate the base-area-to-wetted-area ratio of the respective vehicle at the specific flight condition. From these numbers, in relationship to the curves, note that the data from the vehicles designated by the open symbols (except the M2-F1 vehicle) are in qualitative accord with the semiempirical curves. As was stated earlier with regard to figure 8 , overall $C_{F_{e}}$ for the M2-F1 vehicle is believed to be lower than the semiempirical curves suggest because turning vanes pressurized the base. For the X-24B vehicle (the dark triangle), the value of $C_{F_{e}}$ is believed to be high because of the aforementioned large flare angle that lowers the lee-side pressures on the longitudinal control body flaps. This belief is not only supported by data from reference 56 but also by speed brake data from the X-15 aircraft (the dark symbol) which represent a comparable flared, or wedge, angle. ${ }^{67}$

\section{The Effect of Fineness Ratio on Drag}

Truncated or blunt-based bodies, such as the subject vehicles, bear a familial relationship to the forward two- thirds or three-fourths of a classical body of revolution that has a fully boat-tailed afterbody (for example, Sears-Haack). Considering whether the subsonic forebody drag of a blunt-based vehicle is dependent on fineness ratio, as is the drag of a fully boat-tailed body, is reasonable. To evaluate this relationship, the forebody drag coefficients $\left(C_{F_{e}}{ }^{\prime}\right)$ of the seven vehicles are plotted with respect to effective fineness ratio $\left(I / d_{e f f}\right)$ in figure 10 . The open symbols show a clear relationship between forebody drag and fineness ratio, although configurational differences other than fineness ratio are likely prominent for fineness ratios less than 3. As stated before for the discussion of figure 7 , the solid triangle symbol representing the $\mathrm{X}-24 \mathrm{~B}$ vehicle shows a much higher forebody drag coefficient because of higher pressure on the windward surface of the body flaps, which are deflected to a large flare or wedge angle. The $\mathrm{X}-15$ forebody drag for partially deflected speed brakes (the solid diamond symbol) is included here because it lends credence to the $\mathrm{X}-24 \mathrm{~B}$ data, and discussion of same, in that the $\mathrm{X}-24 \mathrm{~B}$ body flaps and the $\mathrm{X}-15$ speed brakes experience related flow phenomenon.

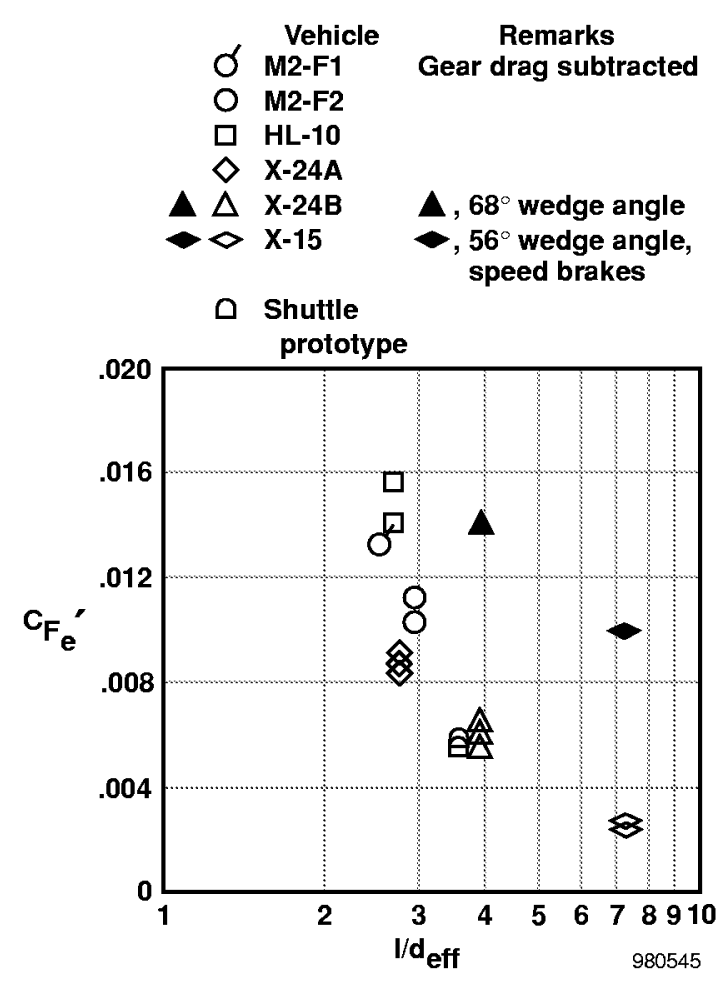

Figure 10. The relationship of forebody equivalent skin friction coefficient with fineness ratio. 


\section{$\underline{\text { Summary of Results }}$}

Flight-determined lift and drag characteristics from seven blunt-based lifting-body and wing-body reentry configurations have been compared and related to several standards of aerodynamic efficiency. For liftcurve slope, limited comparisons are made with generic wind-tunnel model results and the theoretical relationships of Jones and Helmbold. A summary of major results is as follows:

1. Base pressure coefficient data from the $\mathrm{X}-15$, the M2-F3, and the Space Shuttle vehicles indicate that Hoerner's equation relating base pressure to three-dimensional forebody drag requires a larger numerator coefficient in order to represent largescale flight vehicles. A tentative range of values for the numerator coefficient is from 0.09 to 0.10 rather than 0.029 , which is based on small-scale model data.

2. Evidence exists that subsonic flow separating from a relatively large, sharp-edged threedimensional base can exhibit quasi-twodimensional characteristics and base pressure coefficients.

3. The nature of the Hoerner base-pressure-to forebody-drag relationship (regardless of whether his three-dimensional or two-dimensional equation is used, or the numerator coefficient value) causes base drag and forebody drag to combine to form an optimum minimum drag (a drag "bucket") over a small range of forebody drag. The magnitude of forebody drag coefficient that defines the bucket depends on the ratio of base area to wetted area of the respective vehicle. A vehicle having a large base-area-to-wetted-area ratio and a relatively flat upper surface may benefit from surface roughness drag (associated perhaps with a thermal protection system) at low lifting conditions; this combination of features may provide some favorable compensation for low-fineness-ratio vehicles having a relatively large base.

4. Conversely, a strong relationship between forebody drag and fineness ratio (favoring, of course, the higher fineness ratios) has been demonstrated to exist. This characteristic, in concert with the possibility of achieving the aforementioned drag bucket, underlines the importance of obtaining more large-scale free-flight base pressure and forebody drag data. Such an investigation should either confirm the numerator coefficient band suggested herein for the three-dimensional equations ( $K=0.09$ to 0.10 ), confirm or refute the two-dimensional nature of the separating flow, or define a new superior relationship that will reliably define the nature of the drag bucket for general application.

5. Minimum equivalent parasite drag area values for the vehicles range from $6.5 \mathrm{ft}^{2}$ to $164 \mathrm{ft}^{2}$. Division of equivalent drag area by the associated wetted area provided equivalent skin friction coefficients ranging from approximately 0.009 to 0.020 , excluding the less efficient body-flap configurations (these coefficients include base drag). These minimum equivalent skin friction values range from 4 to slightly more than 8 times the skin friction drag for the attached turbulent boundary layer alone.

6. When the base drag coefficient is subtracted from the minimum equivalent friction coefficient (thereby defining forebody drag coefficient), a considerable increment of excess drag above that which would be attributable to an attached turbulent boundary-layer still exists for all of the vehicles except the X-15 aircraft. These equivalent skin friction coefficients, for forebodies, ranged from approximately 1.2 to approximately 6.6 times the skin friction drag for the attached turbulent boundary-layer alone. This extra increment of equivalent friction drag, referred to as excess drag, is believed to result from the following:

- local regions of separated flow upstream of base stations or any trailing edges.

- vortices generated by deflected control surfaces, body crossflow, and in some cases, unproductive sideloads generated by the outboard fins.

- roughness and protuberance effects.

- compressibility effects.

7. Little order existed to the lift-curve slope data when lift coefficient was based on the reference areas used in the reports from which the data were obtained. Application of more representative reference areas (for five of the seven vehicles) and adjustment of the lift-curve slopes for compressibility provided improved order to the data. These data demonstrate that the choice of a physically meaningful (representative) reference area is of major importance.

8. The M2-F2 data demonstrate that the lift-curve slope of very-low-aspect-ratio lifting bodies can 
exceed the lift-curve slope values represented by the relationships of Jones or Helmbold for aspect ratios less than approximately 1 . The M2-F2 results are not believed to be an anomaly because they are afforded credence by generic model results as well as by generic leading-edge vortex lift data and crossflow lift data.

9. Excepting the M2-F1 and the HL-10 vehicles, the remaining five vehicles form an array (a band of $(L / D)_{\max }$ over a range of $\left.b^{2} / A_{w}\right)$ that should be a useful reference source against which to relate future reentry-type vehicles.

\section{$\underline{\text { References }}$}

${ }^{1}$ National Advisory Committee for Aeronautics, NACA Conference on High-Speed Aerodynamics: A Compilation of the Papers Presented, NASA TM-X-67369, 1958.

${ }^{2}$ Faget, Maxime A., Benjamine J. Garland, and James J. Buglia, "Preliminary Studies of Manned Satellites -Wingless Configuration: Nonlifting," NACA Conference on High-Speed Aerodynamics: A Compilation of the Papers Presented, NASA TM-X-67369, 1958, pp. 19-33.

${ }^{3}$ Wong, Thomas J., Charles A. Hermach, John O. Reller, Jr., and Bruce E. Tinling, "Preliminary Studies of Manned Satellites-Wingless Configurations: Lifting Body," NACA Conference on High-Speed Aerodynamics: A Compilation of the Papers Presented, NASA TM-X-67369, 1958, pp. 35-44.

${ }^{4}$ Becker, John V., "Preliminary Studies of Manned Satellites-Winged Configurations," NACA Conference on High-Speed Aerodynamics: A Compilation of the Papers Presented, NASA TM-X-67369, 1958, pp. 45-57.

${ }^{5}$ Chapman, Dean R., "Study of Motion and Heating for Entry Into Planetary Atmospheres," NACA Conference on High-Speed Aerodynamics: A Compilation of the Papers Presented, NASA TM-X-67369, 1958, pp. 1-17.

${ }^{6}$ Love, Eugene S., "Introductory Considerations of Manned Reentry Orbital Vehicles," Joint Conference on Lifting Manned Hypervelocity and Reentry Vehicles: A Compilation of the Papers Presented, NASA TM-X-67563, 1960, pp. 39-54.

${ }^{7}$ Dennis, David H. and George G. Edwards, "The Aerodynamic Characteristics of Some Lifting Bodies,"
Joint Conference on Lifting Manned Hypervelocity and Reentry Vehicles: A Compilation of the Papers Presented, NASA TM-X-67563, 1960, pp. 103-119.

${ }^{8}$ Paulson, John W., Robert E. Shanks, and Joseph L. Johnson, "Low-Speed Flight Characteristics of Reentry Vehicles of the Glide-Landing Type," Joint Conference. on Lifting Manned Hypervelocity and Reentry Vehicles: A Compilation of the Papers Presented, NASA TM-X-67563, 1960, pp. 329-344.

${ }^{9}$ Reed, R. Dale with Darlene Lister, Wingless Flight: The Lifting Body Story, NASA SP-4220, 1997.

${ }^{10}$ Horton, Victor W., Richard C. Eldredge, and Richard E. Klein, Flight-Determined Low-Speed Lift and Drag Characteristics of the Lightweight M2-F1 Lifting Body, NASA TN-D-3021, 1965.

${ }^{11}$ Smith, Harriet J., Evaluation of the LateralDirectional Stability and Control Characteristics of the Lightweight M2-F1 Lifting Body at Low Speeds, NASA TN-D-3022, 1965.

${ }^{12}$ Pyle, Jon S. and Robert H. Swanson, Lift and Drag Characteristics of the M2-F2 Lifting Body During Subsonic Gliding Flight, NASA TM-X-1431, 1967.

${ }^{13}$ Pyle, Jon S., Lift and Drag Characteristics of the HL-10 Lifting Body During Subsonic Gliding Flight, NASA TN-D-6263, 1971.

${ }^{14}$ Ash, Lawrence G., Flight Test and Wind Tunnel Performance Characteristics of the X-24A Lifting Body, FTC-TD-71-8, June 1972.

${ }^{15}$ United States Air Force, Comparison of Flight Test and Wind Tunnel Performance Characteristics of the X-24B Research Aircraft, AFFTC-TR-76-10, Apr. 1976.

${ }^{16}$ Flight Test Results Pertaining to the Space Shuttlecraft, NASA TM-X-2101, 1970.

${ }^{17}$ Aerodynamics of Hypersonic Lifting Vehicles, AGARD-CP-428, Apr. 1987.

${ }^{18}$ Kempel, Robert W., Weneth D. Painter, and Milton O. Thompson, Developing and Flight Testing the HL-10 Lifting Body: A Precursor to the Space. Shuttle, NASA RP-1332, 1994.

${ }^{19}$ Matranga, Gene J., Analysis of X-15 Landing Approach and Flare Characteristics Determined From the First 30 Flights, NASA TN-D-1057, 1961. 
${ }^{20}$ Matranga, Gene J. and Neil A. Armstrong, Approach and Landing Investigation at Lift-Drag Ratios of 2 to 4 Utilizing a Straight-Wing Fighter Airplane, NASA TM-X-31, 1959.

${ }^{21}$ Saltzman, Edwin J. and Darwin J. Garringer, Summary of Full-Scale Lift and Drag Characteristics of the X-15 Airplane, NASA TN-D-3343, 1966.

${ }^{22}$ Thompson, Milton O., "Final Remarks and Future Plans," Flight Test Results Pertaining to the Space. Shuttlecraft, NASA TM-X-2101, 1970, pp. 147-151.

\footnotetext{
${ }^{23}$ United States Air Force, AFFTC Evaluation of the
} Space Shuttle Orbiter and Carrier Aircraft: NASA Approach and Landing Test, AFFTC-TR-78-14, May 1978.

${ }^{24}$ Krienes, Klaus, The Elliptic Wing Based on the Potential Theory, NACA TM-971, 1941.

${ }^{25}$ Helmbold, H. B., "Der unverwundene Ellipsenflugel als tragende Flache," Jahrb, 1942 der Deutschen Luftfahrtforschung, R. Oldenbourg (Munich), pp. I-111-I-113.

${ }^{26}$ Polhamus, Edward C., A Simple Method of Estimating the Subsonic Lift and Damping in Roll of Sweptback Wings, NACA TN-1862, 1949.

${ }^{27}$ Jones, Robert T., Properties of Low-Aspect-Ratio Pointed Wings at Speeds Below and Above the Speed of Sound, NACA Report 835, 1946.

${ }^{28}$ Brown, Clinton E. and Michael, William H., Jr., On Slender Delta Wings with Leading-Edge. Separation, NACA TN-3430, 1955.

${ }^{29}$ Allen, H. Julian and Edward W. Perkins, A Study of Effects of Viscosity on Flow Over Slender Inclined Bodies of Revolution, NACA Report 1048, 1951.

${ }^{30}$ Hoerner, Sighard F. and Henry V. Borst, FluidDynamic Lift: Practical Information on Aerodynamic and Hydrodynamic Lift, published by Liselotte A. Hoerner, 1985.

\footnotetext{
${ }^{31}$ Hoerner, Sighard F., Fluid-Dynamic Drag: Practical Information on Aerodynamic Drag and Hydrodynamic Resistance, Published by the author, 1965.

${ }^{32}$ Oswald, W. Bailey, General Formulas and Charts for the Calculation of Airplane Performance, NACA Report 408, 1932.
}

${ }^{33}$ Wendt, R. E., "A Method of Airplane Performance Calculation Applicable to Any Polar," Journal of the Aeronautical Sciences, vol. 14, no. 4, Apr. 1947, pp. 243-250.

${ }^{34}$ Raymer, Daniel P., Aircraft Design: A Conceptual Approach, AIAA Education Series, 1992.

${ }^{35}$ Stinton, Darrol, The Design of the Aeroplane, Van Nostrand Rheinhold Company, New York, 1983.

${ }^{36}$ Loftin, Laurence K., Jr., Subsonic Aircraft: Evolution and the Matching of Size to Performance, NASA RP-1060, 1980.

${ }^{37}$ Perkins, Courtland D. and Robert E. Hage, Airplane Performance Stability and Control, John Wiley and Sons, New York, 1949.

${ }^{38}$ Peterson, John B., Jr., A Comparison of Experimental and Theoretical Results for the Compressible Turbulent-Boundary-Layer Skin Friction With Zero Pressure Gradient, NASA TN-D-1795, 1963.

${ }^{39}$ Bertram, Mitchel H., Calculations of Compressible Average Turbulent Skin Friction, NASA TR-R-123, 1962.

${ }^{40}$ Saltzman, Edwin J., Base Pressure Coefficients Obtained From the X-15 Airplane for Mach Numbers up to 6, NASA TN-D-2420, 1964.

${ }^{41}$ Research-Airplane-Committee Report on Conference on the Progress of the X-15 Project: A Compilation of the Papers Presented, NASA TM-X-57072, 1961.

${ }^{42}$ Watts, Joe D. and Ronald P. Banas, X-15 Structural Temperature Measurements and Calculations for Flights to Maximum Mach Numbers of Approximately 4, 5, and 6, NASA TM-X-883, 1963.

${ }^{43}$ Gord, P. R., Measured and Calculated Structural Temperature Data From Two X-15 Airplane Flights With Extreme Aerodynamic Heating Conditions, NASA TM-X-1358, 1967.

\footnotetext{
${ }^{44}$ Pearson, Henry A. and Dorothy E. Beadle, Flight Measurements by Various Methods of the Drag Characteristics of the XP-5I Airplane, NACA MR-L6F12, 1946.

${ }^{45}$ Beeler, De E., Donald R. Bellman, and Edwin J. Saltzman, Flight Techniques for Determining Airplane. Drag at High Mach Numbers, NACA TN-3821, 1956.
} 
${ }^{46}$ Ware, George M., Low-Subsonic-Speed Static Stability of Right-Triangular-Pyramid and Half-Cone. Lifting Reentry Configurations, NASA TN-D-646, 1961.

${ }^{47}$ Stivers, Louis S., Jr. and Lionel L. Levy, Jr., Longitudinal Force and Moment Data at Mach Numbers From 0.60 to 1.40 for a Family of Elliptic Cones With Various Semiapex Angles, NASA TN-D-1149, 1961.

${ }^{48}$ Pyle, Jon S. and Lawrence C. Montoya, Effect of Roughness of Simulated Ablated Material on LowSpeed Performance Characteristics of a Lifting-Body Vehicle, NASA TM-X-1810, 1969.

${ }^{49}$ Layton, Garrison P. Jr., Interim Results of the Lifting-Body Flight-Test Program, NASA TM-X-1827, 1969.

${ }^{50}$ Gothert, B., Plane and Three-Dimensional Flow at High Subsonic Speeds, NACA TM-1105, 1946.

${ }^{51}$ DeYoung, John and Charles W. Harper, "Theoretical Symmetric Span Loading at Subsonic Speeds for Wings Having Arbitrary Plan Form," Thirtyfourth Annual Report of the National Advisory Committee for Aeronautics: 1948, 1951, pp. 593-648.

${ }^{52}$ Roskam, Jan, Airplane Design, Part VI: Preliminary Calculation of Aerodynamic, Thrust and Power Characteristics, Roskam Aviation and Engineering Corporation, Ottawa, Kansas, 1990.

${ }^{53}$ Hoey, Robert G., Flight Test Handling Qualities of the X-24A Lifting Body, FTC-TD-71-11, Feb. 1973.

${ }^{54}$ Nagy, Christopher J. and Paul W. Kirsten, Handling Qualities and Stability Derivatives of the X-24B Research Aircraft, AFFTC-TR-76-8, Mar. 1976.

${ }^{55}$ United States Air Force, Correlation of X-24B Flight and Wind Tunnel Pressure Data, AFFDL-TR-78-93, Sept. 1978.

${ }^{56}$ Butsko, J. E., W. V. Carter, and W. Herman, Development of Subsonic Base Pressure Prediction Methods, AFFDL-TR-65-157, vol. 1, Aug. 1965.

${ }^{57}$ Kirsten, Paul W., David F. Richardson, and Charles M. Wilson, "Predicted and Flight Test Results of the Performance, Stability and Control of the Space Shuttle
From Reentry to Landing," Shuttle Performance: Lessons Learned, NASA CP-2283, part 1, 1983, pp. 509-524.

${ }^{58}$ Phillips, W. P., H. R. Compton, and J. T. Findlay, "Base Drag Determination for STS Flights 1-5" AIAA-83-2719, Nov. 1983.

${ }^{59}$ Whitmore, Stephen A. and Timothy R. Moes, "Drag Measurements on the LASRE Flight Experiment and Their Relevance to the X-33," AIAA-99-0277, to be presented at the 37th AIAA Aerospace Sciences Meeting and Exhibit, Reno, Nevada, January 11-14, 1999.

${ }^{60}$ Nash, J. F., A Discussion of Two-Dimensional Turbulent Base Flows, NPL Aero Report 1162, July 1965.

${ }^{61}$ Pollock, N., Some Effects of Base Geometry on Two Dimensional Base Drag at Subsonic and Transonic Speeds, Department of Supply, Australian Defence Scientific Service Aeronautical Research Laboratories, Aerodynamics Note 316, Oct. 1969.

${ }^{62}$ Tanner, M., "Reduction of Base Drag," Progressive Aerospace Science, vol. 16, no. 4, 1975, pp. 369-384.

${ }^{63}$ Tanner, M., "A Method for Reducing the Base Drag of Wings With Blunt Trailing Edge," Aeronautical Quarterly, vol. 23, no. 1, Feb. 1972, pp. 15-23.

${ }^{64}$ Saltzman, Edwin J. and John Hintz, Flight Evaluation of Splitter-Plate Effectiveness in Reducing Base Drag at Mach Numbers From 0.65 to 0.90 , NASA TM-X-1376, 1967.

${ }^{65}$ Tanner, Mauri, "New Investigations for Reducing the Base Drag of Wings With a Blunt Trailing Edge," Aerodynamic Drag, AGARD-CP-124, Apr. 1973, pp. 12-1-12-9.

${ }^{66}$ Pyle, Jon S. and Edwin J. Saltzman, "Review of Drag Measurements From Flight Tests of Manned Aircraft With Comparisons to Wind-Tunnel Predictions," Aerodynamic Drag, AGARD-CP-124, Apr. 1973, pp. 25-1-25-12.

${ }^{67}$ Saltzman, Edwin J., Preliminary Full-Scale PowerOff Drag of the X-15 Airplane for Mach Numbers From 0.7 to 3.1, NASA TM-X-430, 1960. 
Public reporting burden for this collection of information is estimated to average 1 hour per response, including the time for reviewing instructions, searching existing data sources, gathering and maintaining the data needed, and completing and reviewing the collection of information. Send comments regarding this burden estimate or any other aspect of this collection of information, including suggestions for reducing this burden, to Washington Headquarters Services, Directorate for Informatıon Operations and Reports, 1215 Jefferson Davis Highway, Suite 1204, Arlington, VA 22202-4302, and to the Office of Management and Budget, Paperwork Reduction Project (0704-0188), Washington, DC 20503.

1. AGENCY USE ONLY (Leave blank)

2. REPORT DATE January 1999
3. REPORT TYPE AND DATES COVERED

Conference Paper

4. TITLE AND SUBTITLE

Flight-Determined Subsonic Lift and Drag Characteristics of Seven

Lifting-Body and Wing-Body Reentry Vehicle Configurations With

Truncated Bases

6. AUTHOR(S)

529-50-04-T2-RR-00-000

Edwin J. Saltzman, K. Charles Wang, and Kenneth W. Iliff.

7. PERFORMING ORGANIZATION NAME(S) AND ADDRESS(ES)

NASA Dryden Flight Research Center

P.O. Box 273

Edwards, California 93523-0273

8. PERFORMING ORGANIZATION

REPORT NUMBER

H-2287

9. SPONSORING/MONITORING AGENCY NAME(S) AND ADDRESS(ES)

10. SPONSORING/MONITORING AGENCY REPORT NUMBER

National Aeronautics and Space Administration

Washington, DC 20546-0001

H-2287

11. SUPPLEMENTARY NOTES

Presented as AIAA 99-0383 at the 37th AIAA Aerospace Sciences Meeting and Exhibit, Reno, Nevada, January 11-14, 1999

12a. DISTRIBUTION/AVAILABILITY STATEMENT

12b. DISTRIBUTION CODE

Unclassified-Unlimited

Subject Category 02, 15

13. ABSTRACT (Maximum 200 words)

This paper examines flight-measured subsonic lift and drag characteristics of seven lifting-body and wingbody reentry vehicle configurations with truncated bases. The seven vehicles are the full-scale M2-F1, M2-F2, HL-10, X-24A, X-24B, and X-15 vehicles and the Space Shuttle prototype. Lift and drag data of the various vehicles are assembled under aerodynamic performance parameters and presented in several analytical and graphical formats. These formats unify the data and allow a greater understanding than studying the vehicles individually allows. Lift-curve slope data are studied with respect to aspect ratio and related to generic windtunnel model data and to theory for low- aspect-ratio planforms. The proper definition of reference area was critical for understanding and comparing the lift data. The drag components studied include minimum drag coefficient, lift-related drag, maximum lift-to-drag ratio, and, where available, base pressure coefficients. The effects of fineness ratio on forebody drag were also considered. The influence of forebody drag on afterbody (base) drag at low lift is shown to be related to Hoerner's compilation for body, airfoil, nacelle, and canopy drag. These analyses are intended to provide a useful analytical framework with which to compare and evaluate new vehicle configurations of the same generic family.

14. SUBJECT TERMS

Aerodynamics, Lifting bodies, Reentry vehicles, Reusable launch vehicles

32

16. PRICE CODE

A03

17. SECURITY CLASSIFICATION

OF REPORT

Unclassified

NSN 7540-01-280-5500

\begin{tabular}{l|l}
\hline $\begin{array}{l}\text { 18. SECURITY CLASSIFICATION } \\
\text { OF THIS PAGE }\end{array}$ & $\begin{array}{c}\text { 19. SECURITY CLASSIFICATION } \\
\text { OF ABSTRACT } \\
\text { Unclassified }\end{array}$ \\
& Unclassified
\end{tabular}

Unclassified
20. LIMITATION OF ABSTRACT

Unlimited

Standard Form 298 (Rev. 2-89) Prescribed by ANSI Std. Z39-18 298-102 